\title{
Three-Dimensional Structure of Tropical Cells in the Central Equatorial Pacific Ocean*
}

\author{
Renellys C. Perez And William S. Kessler \\ NOAA/Pacific Marine Environmental Laboratory, Seattle, Washington
}

(Manuscript received 11 April 2008, in final form 23 June 2008)

\begin{abstract}
The shallow tropical cells (TCs) in the central equatorial Pacific Ocean are characterized by strong equatorial upwelling, near-surface wind-driven poleward flow, downwelling near the cold tongue boundaries, and equatorward flow below the surface mixed layer. Meridional and vertical velocity fluctuations associated with tropical instability waves (TIWs) in the central equatorial Pacific are much larger than those associated with the TCs and can modify the background circulation. OGCM experiments are used to simulate the spinup of the cells along $140^{\circ} \mathrm{W}$ in response to perturbed trade winds during various phases of the annual cycle. Equatorially modified versions of geostrophy and Ekman theory, and zonal filtering, are used to isolate the large-zonal-scale wind-driven response. Weakening of the trade winds in any season rapidly weakens the TCs, decreases the zonal current shear, and reduces the amplitude and propagation speed of the TIWs. In boreal fall and winter, when the background TCs and TIWs are seasonally strong, the ocean response is equatorially asymmetric (stronger flows north of the equator) and there is evidence of rectification by the modified TIWs onto the TCs. The linear equatorially modified Ekman solutions largely explain the meridional structure and temporal evolution of the anomalous ageostrophic response in the TCs. In fall and winter, however, deviations from the modified Ekman solutions were attributed to interactions with the background TCs and TIWs. An observing system able to quantify the relative contributions of these two processes to the seasonally varying equatorial asymmetry of background circulation would require fine meridional and temporal sampling.
\end{abstract}

\section{Introduction}

Although much is known about upper ocean horizontal currents along the equator between $165^{\circ} \mathrm{E}$ and $110^{\circ} \mathrm{W}$ from multidecadal Tropical Ocean Atmosphere (TAO) horizontal velocity measurements (Hayes et al. 1991; McPhaden 1993), long-term measurements of the meridional upwelling circulation cells in the central equatorial Pacific Ocean do not exist. Our picture of these tropical cells (TCs) is derived primarily from models ( $\mathrm{Lu}$ et al. 1998; Hazeleger et al. 2001; Brown et al. 2007a,b), which are poorly constrained by obser-

\footnotetext{
* Pacific Marine Environmental Laboratory Contribution Number 3200.

Corresponding author address: Renellys C. Perez, National Oceanic and Atmospheric Administration/Atlantic Oceanographic and Meteorological Laboratory, 4301 Rickenbacker Causeway, Miami, FL 33149.

E-mail: renellys.c.perez@noaa.gov
}

vations. These shallow cells are characterized by strong equatorial upwelling, near-surface wind-driven poleward divergence, downwelling near the northern and southern boundaries of the cold tongue, and equatorial convergence of geostrophic flow below the surface mixed layer. Equatorial upwelling and meridional heat advection by the TCs play an important role in the cold tongue heat balance (Wyrtki 1981; Swenson and Hansen 1999; Wang and McPhaden 1999; de Szoeke et al. 2007), and a better understanding of these currents is required to accurately model the cold tongue region and its impact on the coupled climate system.

The cross-equatorial structure (Johnson and Luther 1994; Johnson et al. 2001; Johnson et al. 2002) and annual and inter-annual evolution (Kessler and Taft 1987; Reverdin et al. 1994; Bonjean and Lagerloef 2002; Johnson et al. 2002) of zonal currents in the central equatorial Pacific have been described using analyses of data from drifters, satellites, shipboard ADCP transects, and moorings, but much less is known about the spatiotemporal structure of the TCs. Westward 
propagating tropical instability waves (TIWs), which have periods ranging from 15 to 40 days (Qiao and Weisberg 1995; Lyman et al. 2007, and references therein) and zonal wavelengths on the order of $1000 \mathrm{~km}$ (Legeckis 1977; Qiao and Weisberg 1995), produce large-amplitude velocity fluctuations in the central and eastern equatorial Pacific that are much larger than the background TCs (Weisberg and Qiao 2000). The highfrequency variability induced by TIWs also dominates over the low-frequency variability associated with the annual cycle of the TCs (Reverdin et al. 1994; Kessler et al. 1998; Bonjean and Lagerloef 2002), posing a difficult sampling problem.

Weisberg and Qiao (2000) found that poleward divergence and upwelling at $0^{\circ}, 140^{\circ} \mathrm{W}$ are strongest when the southeasterly trade winds are strong (late boreal summer to fall). Depiction of the mean TCs from 85 shipboard ADCP transects between $170^{\circ}$ and $95^{\circ} \mathrm{W}$ required averaging over $75^{\circ}$ longitude and 9 years, and additional smoothing over $2^{\circ}$ latitude bins, to limit aliasing by the TIWs (Johnson et al. 2001, hereafter JMF). Nevertheless, JMF found that the mean TCs near $140^{\circ} \mathrm{W}$ are equatorially asymmetric, with stronger poleward flow and off-equatorial downwelling in the northern cell. How this equatorial asymmetry of the TCs varies annually and interannually is unknown. Yet it is likely that such variability will be found because the speed and meridional structure of the zonal currents vary substantially seasonally and interannually (Kessler and Taft 1987; Reverdin et al. 1994; Bonjean and Lagerloef 2002; Johnson et al. 2002).

Modeling studies suggest that the shear between the northern branch of the westward flowing South Equatorial Current (SECN) and eastward flowing North Equatorial Countercurrent (NECC) is a source of energy for the TIWs (Philander 1978; Cox 1980; Donohue and Wimbush 1998; Lyman et al. 2005). This shear is strongest in boreal fall and winter (Reverdin et al. 1994; Bonjean and Lagerloef 2002; Johnson et al. 2002) and during La Niña conditions (Johnson et al. 2002). TIWs, which have larger amplitudes north of the equator (Chelton et al. 2000; Chelton et al. 2001; Lyman et al. 2007), are also most energetic at these times (Baturin and Niiler 1997; Kessler et al. 1998; Contreras 2002; Lyman et al. 2007). We hypothesize that low-frequency variations in the asymmetric zonal currents and their effect on the TIWs produce low-frequency variations in the asymmetry of the TCs, specifically that there is nonlinear rectification by the TIWs onto the TCs.

In lieu of adequate cross-equatorial observations showing the TCs, ocean general circulation models (OGCMs) can be used to study their three-dimensional structure and modification by varying winds and TIWs. In this paper, an OGCM is used to describe the spinup of the TCs along $140^{\circ} \mathrm{W}$ in response to perturbed trade winds during different phases of the seasonal cycle and different stages of TIW development. Findings from this study will aid in the design of future field experiments in the cold tongue region. In that spirit, model fields are analyzed in $z$ coordinates rather than density coordinates (Hazeleger et al. 2001; Brown et al. 2007a,b), as simultaneous ocean measurements of cross-equatorial velocity and density are not readily available. Our expectation was that these simple wind experiments would produce a quasi-linear ocean response that would be distinguishable above the TIW "noise." We found instead that the response of the TCs to anomalous winds was more complex and that the equatorial asymmetry of the response was sensitive to the seasonally varying strength of the background TCs and TIWs.

Section 2 describes the numerical model, wind experiments, equatorial geostrophic calculations introduced to separate the ageostrophic circulation from that driven by pressure gradients, and the filtering applied to remove the small-zonal-scale TIW response. This filtering allows us to focus on the large-zonal-scale response of the TCs to the anomalous winds but does not remove large-zonal-scale changes to the TCs due to nonlinear interactions with the TIWs. An equatorially modified model of Ekman transports and vertical velocity introduced in section 2 is used to interpret the ageostrophic response. Section 3 compares the anomalous circulation during times of the year when the background winds, TCs, and TIWs are all either weak or strong. How the meridional structure and temporal evolution of the ageostrophic response differ from those of the linear wind-driven response is also examined in section 3 . The linearity and meridional structure of the ageostrophic response are further evaluated in section 4 , and the results are summarized in section 5 .

\section{Numerical experiments}

The OGCM used in this tropical Pacific study is version 4 of the Modular Ocean Model (MOM4) (Griffies et al. 2003). The model implementation closely resembles OM3.1 described by Griffies et al. (2005) and Wittenberg et al. (2006); substantive changes are described below. The model horizontal $\mathrm{B}$ grid spans the tropical Pacific from $40^{\circ} \mathrm{S}$ to $40^{\circ} \mathrm{N}, 120^{\circ} \mathrm{E}$ to $60^{\circ} \mathrm{W}$ with resolution $0.33^{\circ}$ latitude by $0.625^{\circ}$ longitude in the waveguide. The meridional resolution gradually stretches to $1^{\circ}$ at $40^{\circ}$ latitude. The model has $49 z$ levels 
with vertical spacing of $10 \mathrm{~m}$ in the upper $220 \mathrm{~m}$ stretching to $390 \mathrm{~m}$ at the deepest $z$ level. Bottom topography is specified from the Southampton Oceanography Centre maps of ocean floor relief with maximum depth set to $5600 \mathrm{~m}$. We found that the large alongstream viscosities in the waveguide produced by the original OM3.1 horizontal viscosity scheme (Large et al. 2001; Griffies et al. 2005) generated predictable TIWs that repeated exactly from one year to the next (i.e., forced waves). This scheme was therefore deemed unsuitable for analysis of modification of the TCs by TIWs. Instead, we use an anisotropic Laplacian viscosity scheme with constant alongstream and cross-stream viscosities of $2000 \mathrm{~m}^{2} \mathrm{~s}^{-1}$ and $1000 \mathrm{~m}^{2} \mathrm{~s}^{-1}$, respectively, which produces vigorous and realistic TIWs. The model is initialized from rest with temperature and salinity from the Polar Science Center Hydrographic Climatology (PHC; Steele et al. 2001) and spun up with climatological forcing (section 2a). The zonal wind experiments (section $2 b)$ are begun on year 17 of the climatological run.

\section{a. Climatological forcing}

The climatological wind stress is generated by fitting an annual and semiannual harmonic to Quick Scatterometer (QuikSCAT) monthly mean wind stress from September 1999 to August 2005 [an early version of the Risien and Chelton (2008) QuikSCAT climatology]. The QuikSCAT climatology is available on a $0.25^{\circ}$ latitude by $0.25^{\circ}$ longitude grid with $2^{\circ}$ latitude by $2^{\circ}$ longitude loess smoothing (Schlax and Chelton 1992; Risien and Chelton 2008) and is bilinearly interpolated to the model grid. The high spatial resolution of the QuikSCAT climatology resolves the intense zonal bands of wind stress divergence and curl near the equator, and temporal smoothing by the harmonic fit removes small-scale noise associated with local wind coupling to TIWs (Chelton et al. 2001; Risien and Chelton 2008).

Radiative and turbulent surface heat fluxes used to force the climatological run are obtained from the Massachusetts Institute of Technology-Woods Hole Oceanographic Institution (MIT-WHOI) Objectively Analyzed Air-Sea Fluxes (OAFlux) project for the global oceans. Monthly mean surface heat flux composites of objectively analyzed daily surface latent and sensible heat fluxes from 1 January 1981 to 31 December 2002 (Yu et al. 2004; Yu and Weller 2007) and International Satellite Cloud Climatology Project (ISCCP) longwave and shortwave radiation from 1 July 1983 to 31 December 2004 (Zhang et al. 2004) provide the surface forcing. Model SST is damped to climatological SST, based on monthly Tropical Rainfall Measuring
Mission (TRMM) Microwave Imager (TMI) data from September 1999 to October 2005, with a 30-day time scale. A spatially varying mean adjustment term is added to the net surface heat flux to keep the model warm pool and ITCZ from becoming too warm (its magnitude is less than $20 \mathrm{~W} \mathrm{~m}^{-2}$ cooling in the cold tongue). The adjusted net surface heat flux averaged between $5^{\circ} \mathrm{S}$ and $5^{\circ} \mathrm{N}$ compares well with the tropical Pacific annual mean surface heat flux from coupled Geophysical Fluid Dynamics Laboratory (GFDL) global climate simulations and observations (see the heat flux comparison in Fig. 6 of Wittenberg et al. 2006). At lateral boundaries, a solid wall boundary condition is specified and model temperature and salinity are restored to PHC climatological temperature and salinity in a $15^{\circ}$-latitude-wide sponge region with a 30-day damping time scale at the poleward boundary. Sea surface salinity (SSS) is everywhere relaxed to PHC SSS with a 30-day time scale, and zero net water flux is assumed.

Figure 1 compares the annual mean circulation from the climatological run along $140^{\circ} \mathrm{W}(\operatorname{Mod} u, v, w)$ with the observed mean circulation from JMF (Obs $u, v, w)$. Mean zonal currents compare reasonably well with observed currents, with adequate realism in the Equatorial Undercurrent (EUC), NECC, and both branches of the SEC (Figs. 1a,b). However, the mean model SECN and NECC are 10 to $20 \mathrm{~cm} \mathrm{~s}^{-1}$ weaker than estimated by JMF, and the model EUC core is approximately 10 $\mathrm{cm} \mathrm{s}^{-1}$ stronger and $10 \mathrm{~m}$ deeper than observed.

Despite large error bars associated with observed TCs, the following qualitative comparisons can be made. JMF found maximum equatorial upwelling at 50 $\mathrm{m}$ of $1.6 \mathrm{~m} \mathrm{day}^{-1}$, surface poleward flows reaching -9 $\mathrm{cm} \mathrm{s}^{-1}$ in the south and $13 \mathrm{~cm} \mathrm{~s}^{-1}$ in the north, maximum downwelling at $50 \mathrm{~m}$ of $-0.8 \mathrm{~m}^{-1 a y}{ }^{-1}$ near $4.5^{\circ} \mathrm{S}$ and $-1.4 \mathrm{~m} \mathrm{day}^{-1}$ near $8^{\circ} \mathrm{N}$, and maximum equatorward flow at $85-\mathrm{m}$ depth of $5 \mathrm{~cm} \mathrm{~s}^{-1}$ near $1.5^{\circ} \mathrm{S}$ and $-4 \mathrm{~cm} \mathrm{~s}^{-1}$ near $3.5^{\circ} \mathrm{N}$ (Figs. 1d,f,h). Note the vertical banding in JMF's estimate of $w$ below $100 \mathrm{~m}$ (Fig. 1f), which is due to the downward integration of errors in $-(\partial u / \partial x+\partial v / \partial y)$. The model TCs are more asymmetric, with mean meridional currents up to $8 \mathrm{~cm} \mathrm{~s}^{-1}$ faster than observed in and below the surface limb of the northern TC (Figs. 1c,d). Consistent with JMF, the model $w$ is dominated by the vertical integral of $-\partial v / \partial y$ with upwelling (downwelling) where the meridional flow diverges (converges) (Figs. 1e,f). However, the model's upwelling is $1.4 \mathrm{~m}^{\text {day }}{ }^{-1}$ stronger than observed and the model exhibits paired maxima at $0.7^{\circ} \mathrm{S}$, $70 \mathrm{~m}$ and $1.3^{\circ} \mathrm{N}, 40 \mathrm{~m}$, while the model's off-equatorial downwelling occurs equatorward of the observed 

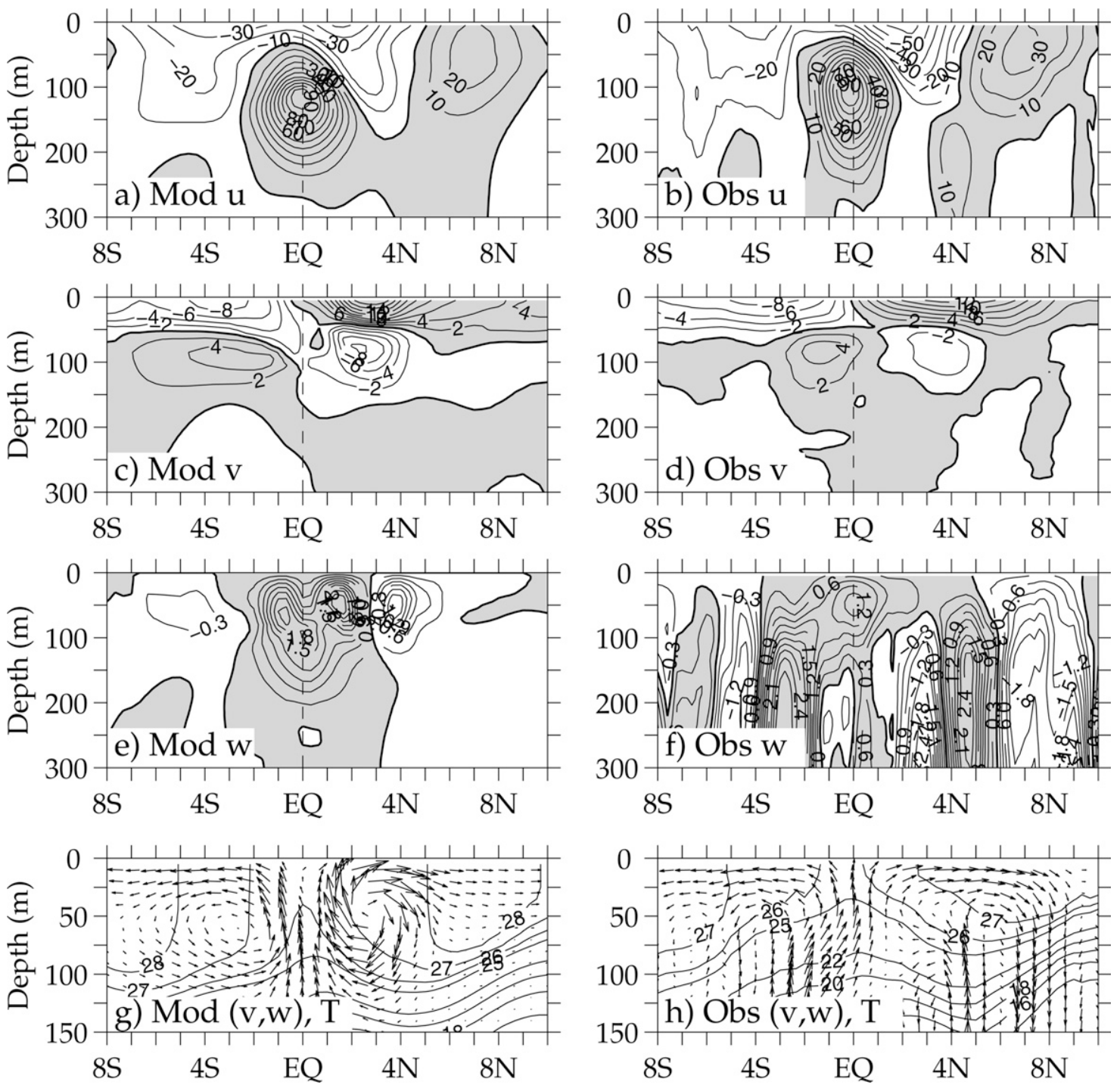

FIG. 1. Mean circulation along $140^{\circ} \mathrm{W}$ from MOM4 simulation driven by climatological forcing compared with mean circulation along $136^{\circ} \mathrm{W}$ estimated from 85 meridional ADCP transects (reproduced from Johnson et al. 2001). Contour intervals for mean $u, v$, and $w$ are $10 \mathrm{~cm} \mathrm{~s}^{-1}, 2 \mathrm{~cm} \mathrm{~s}^{-1}$, and $0.3 \mathrm{~m} \mathrm{day}^{-1}$, respectively. Thick solid line corresponds to zero contour and shaded contours indicate positive values. Scaled vectors depict the TCs in the upper $150 \mathrm{~m}$ with select mean temperature contours overlaid.

downwelling $\left(-0.5 \mathrm{~m} \mathrm{day}^{-1}\right.$ at $4.3^{\circ} \mathrm{S} 60 \mathrm{~m}$ and $-2.1 \mathrm{~m}$ day $^{-1}$ at $\left.3.7^{\circ} \mathrm{N}, 50 \mathrm{~m}\right)$. The off-equatorial upwelling double maxima may be a nonlinear rectification by the more intense TIWs, as this does not occur when the model is run with the OM3.1 viscosity scheme (section 2 ). On the other hand, it is unclear whether this feature could have been resolved by JMF given the considerable spatiotemporal averaging.

\section{b. Zonal wind experiments}

To analyze the response of the TCs along $140^{\circ} \mathrm{W}$ to a localized weakening of the southeasterly trade winds, a series of experiments is conducted that adds a westerly wind anomaly in a $15^{\circ}$ zonal patch centered at $140^{\circ} \mathrm{W}$ to the climatological wind stress. The anomalous winds are imposed for 61-day periods during various phases of the seasonal cycle and different stages of TIW development.

The spatiotemporal structure of the zonal wind patch, $\tau_{x}^{\prime}(x, y, t)=S(x, y) T(t)$ is chosen to isolate the response near $140^{\circ} \mathrm{W}$, provide nearly uniform forcing across the waveguide (zero divergence and curl), allow Kelvin and Rossby wave adjustment to occur within the wind patch, and avoid interference in the wind patch 


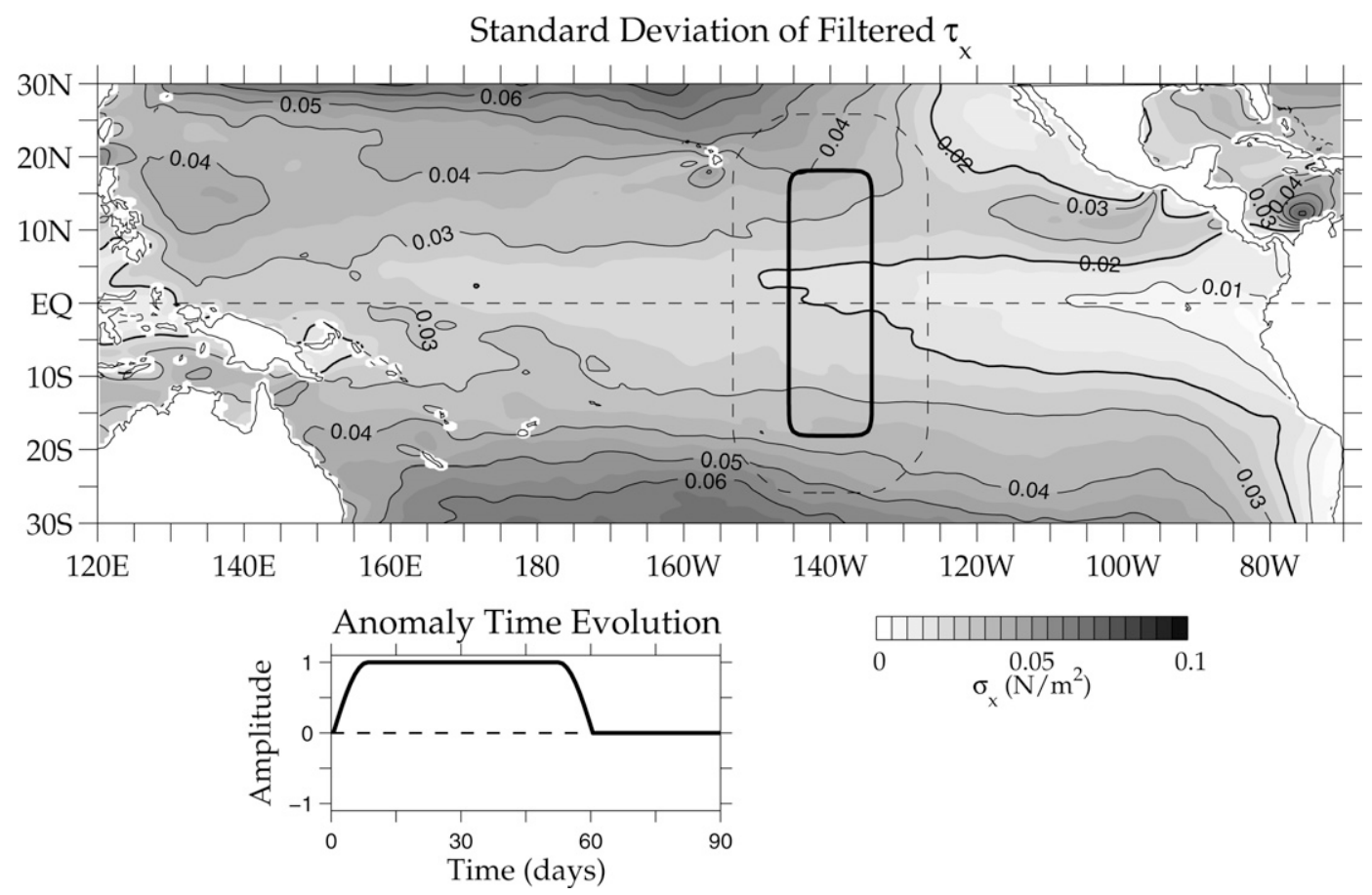

FIG. 2. (top) Standard deviation of QuikSCAT zonal wind stress $\left(\mathrm{N} \mathrm{m}^{-2}\right)$ on intra-annual time scales. Annual cycle removed and 400-day high-pass triangle filter applied to remove annual and interannual variability. Solid box indicates region where anomalous winds approximately equal $A$, and dashed box indicates region where anomalous winds have tapered to zero. (bottom) The temporal evolution of zonal wind anomaly.

from Kelvin waves reflecting off of the Galapagos Islands. The spatial structure $S(x, y)$ is constructed from hyperbolic tangents (Nonaka et al. 2002; Kröger et al. 2005) and has the form

$$
\begin{aligned}
S(x, y)= & \frac{A}{4}\left[\left(\tanh \frac{3\left(x-x_{W}\right)}{L_{x}}-\tanh \frac{3\left(x-x_{E}\right)}{L_{x}}\right)\right. \\
& \left.\times\left(\tanh \frac{3\left(y-y_{S}\right)}{L_{y}}-\tanh \frac{3\left(y-y_{N}\right)}{L_{y}}\right)\right],
\end{aligned}
$$

where $A=0.025 \mathrm{~N} \mathrm{~m}^{-2}(A>0$ is a westerly wind anomaly), $L_{x}=5^{\circ}, L_{y}=5^{\circ}, x_{W}=147.5^{\circ} \mathrm{W}, x_{E}=$ $132.5^{\circ} \mathrm{W}, y_{S}=20^{\circ} \mathrm{S}$, and $y_{N}=20^{\circ} \mathrm{N}$. The magnitude of $A$ was chosen to be typical of the QuikSCAT zonal windstress intra-annual variability (annual cycle and inter annual variability filtered out) near $0^{\circ}, 140^{\circ} \mathrm{W}$ (Fig. 2). The solid box in Fig. 2 indicates the region where the imposed anomalous winds are largest (approximately equal to $A$ ). The temporal evolution of the anomaly is a 45-day rectangle tapered with 8-day sinusoids (Fig. 2, bottom). For several comparisons in sections 3 and 4, results will be averaged over the central 45 days when the full anomaly is applied.
The zonal wind anomalies are superimposed on the climatological wind forcing and used to drive the model during three phases of the annual cycle: boreal winter (starting on 1 January), boreal spring/summer (starting on 1 May), and boreal fall (starting on 1 September). Hereafter, seasons are discussed relative to the Northern Hemisphere annual cycle (e.g., fall implies boreal fall). Differences between the anomaly forced runs and climatological control runs during the same time periods are used to describe the model response to anomalous forcing (i.e., anomalous zonal velocity is defined as $u=u_{\text {total }}-u_{\text {clim }}$, where $u_{\text {total }}$ and $u_{\text {clim }}$ denote the anomaly forced and climatologically forced zonal velocity, respectively). In the control run, as in reality, TIWs are weakest from April to June, grow rapidly in late summer/fall, and persist until March. Similarly, the southeasterly trade winds along $140^{\circ} \mathrm{W}$ are strong in late summer/fall and weaken in late winter (Figs. 3a,b), so the timing of imposed anomalies spans the annual cycle of the winds and the different TIW regimes.

\section{c. Geostrophic currents near the equator}

We use equatorial geostrophy to obtain the pressure gradient-driven part of the response to the imposed wind anomalies. Defining the anomalous dynamic height relative to $500 \mathrm{db}$ to be the difference from 

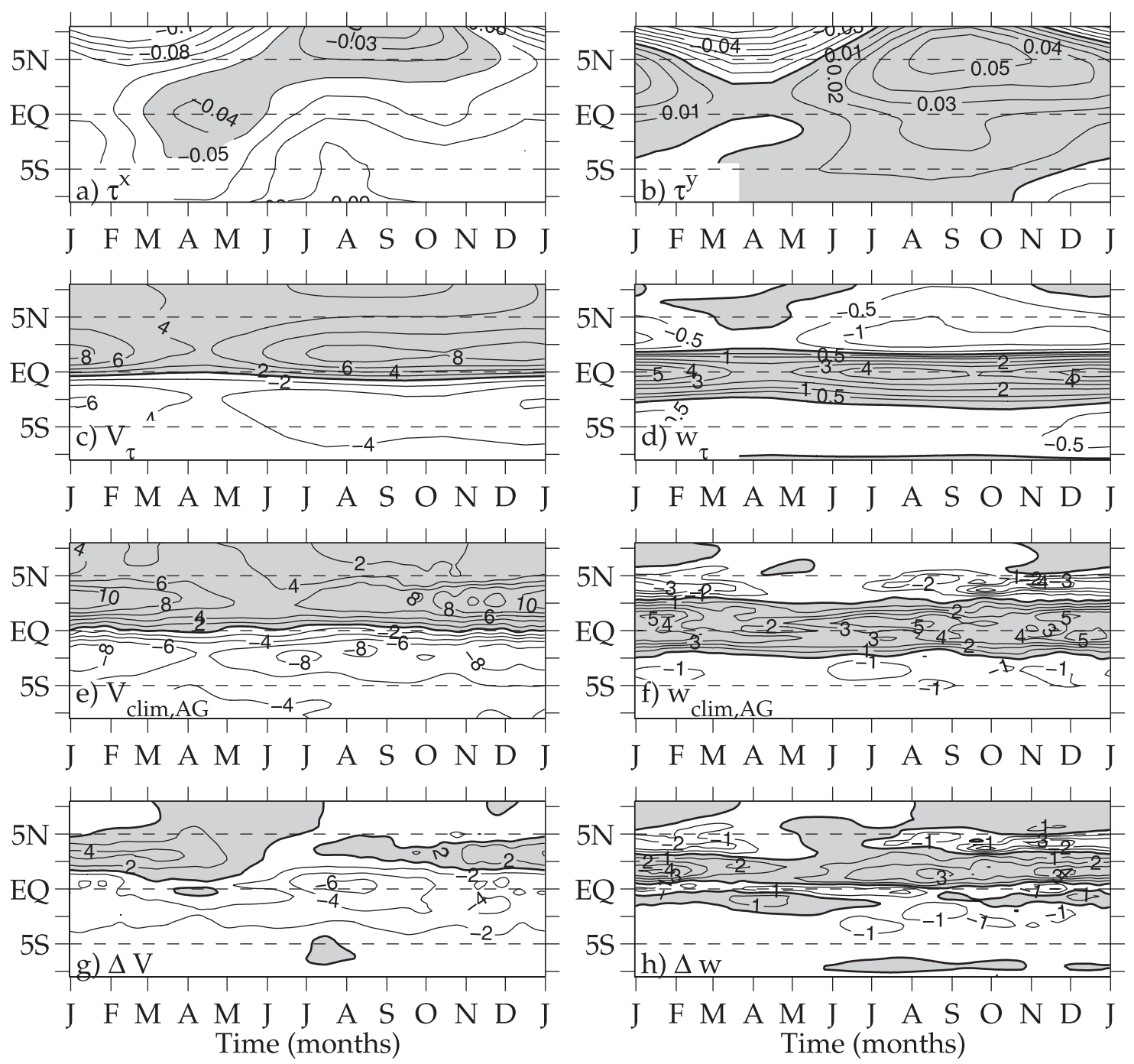

FIG. 3. QuikSCAT windstress climatology $\left(\tau_{x}, \tau_{y}\right)$ along $140^{\circ} \mathrm{W}$. Equatorially modified Ekman meridional transport and vertical velocity computed from those winds $\left(V_{\tau}, w_{\tau}\right)$ are compared with 60-day low-pass-filtered ageostrophic meridional transport and vertical velocity from control run $\left(V_{\text {clim, AG }}, w_{\text {clim }}\right)$. The difference between ageostrophic and equatorially modified Ekman values $(\Delta V, \Delta w)$ is also plotted. Contour intervals for wind stress, transport, and vertical velocity are $0.01 \mathrm{~N} \mathrm{~m}^{-2}, 2 \mathrm{~m}^{2} \mathrm{~s}^{-1}$, and $1 \mathrm{~m} \mathrm{day}^{-1}$ (with addition of $\pm 0.5 \mathrm{~m} \mathrm{day}^{-1}$ contour for $w_{\tau}$ ), respectively. Thick solid line corresponds to zero contour and shaded contours indicate positive values (except for $\tau_{x}$ ).

climatology, $\Phi=\Phi_{\text {total }}-\Phi_{\text {clim }}$, the anomalous geostrophic currents $\left(u_{g}, v_{g}\right)$ are given by (2) away from the equator and (3) along it:

$$
\begin{gathered}
f u_{g}=-g \frac{\partial \Phi}{\partial y}, \quad f v_{g}=g \frac{\partial \Phi}{\partial x} \\
\beta u_{g}=-g \frac{\partial^{2} \Phi}{\partial y^{2}}, \quad \beta v_{g}=g \frac{\partial^{2} \Phi}{\partial x \partial y}
\end{gathered}
$$

where $f=2 \Omega \sin \theta\left(\Omega=7.29 \times 10^{-5} \mathrm{~s}^{-1}, \theta\right.$ is the latitude), $\beta=\partial f / \partial y=2.28 \times 10^{-11} \mathrm{~m}^{-1} \mathrm{~s}^{-1}$, and $g=9.81$ $\mathrm{m} \mathrm{s}^{-2}$. The solutions to these two sets of equations, however, are not continuous at their juncture. To generate a continuous estimate of $u_{g}$ across the equator and preserve the equatorial solution given by (3), an equatorially trapped adjustment term can be added to $\Phi$ such that its meridional gradient, $\partial \Phi / \partial y$, vanishes exactly at the equator (e.g., Picaut and Tournier 1991). As described in the appendix, we introduce an additional adjustment to $\Phi$ to ensure that $v_{g}$ estimated from (2) and (3) is also continuous across the equator. The resulting geostrophic currents compare well with those computed following the method of Lagerloef et al. 
(1999). However, Lagerloef et al. applies a Gaussian adjustment to $\left(u_{g}, v_{g}\right)$ whereas this approach adjusts dynamic height. Anomalous ageostrophic currents are defined as $u_{\mathrm{ag}}=u-u_{g}$ and $v_{\mathrm{ag}}=v-v_{g}$ (see Table 1 for a summary of notation).

\section{d. Equatorially modified Ekman theory}

Classical Ekman theory predicts zonal and meridional transports of the form

$$
\left(U_{e}, V_{e}\right)=\left(\frac{\tau_{y}}{\rho_{0} f}, \frac{-\tau_{x}}{\rho_{0} f}\right)
$$

where $\rho_{0}$ represents a constant density and is chosen to be $1025 \mathrm{~kg} \mathrm{~m}^{-3}$. Ekman vertical velocity $\left(w_{e}\right)$ is computed from the divergence of $\left(U_{e}, V_{e}\right)$. Given the climatological winds $\left(\tau_{x}, \tau_{y}\right)$ along $140^{\circ} \mathrm{W}$ (Figs. 3a,b), this simple linear formulation yields poleward transport that is stronger south of the equator and downwelling that is too strong between $2^{\circ}$ and $5^{\circ}$ latitude in both hemispheres (not shown). Not only is this picture inconsistent with the observed and simulated mean TCs (Fig. 1), the solution also blows up at the equator. An equatorially modified Ekman model (e.g., Lagerloef et al. 1999; Wittenberg 2002) adds linear wind drag to the momentum equations, leading to

$$
\left(U_{\tau}, V_{\tau}\right)=\left[\frac{r_{s} \tau_{x}+f \tau_{y}}{\rho_{0}\left(f^{2}+r_{s}^{2}\right)}, \frac{r_{s} \tau_{y}-f \tau_{x}}{\rho_{0}\left(f^{2}+r_{s}^{2}\right)}\right],
$$

where $r_{s}$ is the vertical shear dissipation rate and $w_{\tau}$ is now computed from the divergence of $\left(U_{\tau}, V_{\tau}\right)$. Note that the linear drag results in downwind transport close to the equator in addition to crosswind transport from the classical formulation (4). Choosing $r_{s}^{-1}=2$ day, as in Wittenberg (2002), yields linear TCs with strong equatorial upwelling, poleward transport that is larger north of the equator, and off-equatorial downwelling between $3^{\circ}$ and $5^{\circ}$ latitude in both hemispheres (Figs. 3c,d). The intensity and equatorial asymmetry of these cells increase when the southeasterly trade winds are strong. The linear equatorially modified Ekman solution agrees well with 60-day lowpass filtered ageostrophic meridional transport and vertical velocity from the climatological control run (Figs. 3e,f). However, places where they differ significantly, noted especially in the northern TC during late summer to early spring, indicate regions where the ocean response is poorly accounted for by linear dynamics (Figs. 3g,h).

For a purely zonal wind anomaly $\tau_{x}^{\prime},\left(U_{\tau}, V_{\tau}\right)$ simplify to

\begin{tabular}{|c|c|}
\hline Symbol & $\begin{array}{c}\text { Description } \\
\text { (section where symbol first appears) }\end{array}$ \\
\hline $\begin{array}{l}u_{\mathrm{clim}}, v_{\mathrm{clim}} \\
w_{\mathrm{clim}}\end{array}$ & $\begin{array}{l}\text { Velocity from climatological control run } \\
\text { (section } 2 \mathrm{~b})\end{array}$ \\
\hline $\begin{array}{l}u_{\text {total }}, v_{\text {total }}, \\
w_{\text {total }}\end{array}$ & $\begin{array}{l}\text { Velocity from anomaly }+ \text { climatological run } \\
\text { (section } 2 \mathrm{~b})\end{array}$ \\
\hline$u, v, w$ & Anomalous velocity (section $2 b$ ) \\
\hline$u_{g}, v_{g}$ & Anomalous geostrophic velocity (section 2c) \\
\hline$u_{\mathrm{ag}}, v_{\mathrm{ag}}$ & Anomalous ageostrophic velocity (section $2 \mathrm{c}$ ) \\
\hline$u_{e}, V_{e}, w_{e}$ & $\begin{array}{l}\text { Ekman transport and vertical velocity } \\
\quad(\text { section } 2 \mathrm{~d})\end{array}$ \\
\hline$u_{\tau}, V_{\tau}, w_{\tau}$ & $\begin{array}{l}\text { Equatorially modified Ekman transport and } \\
\text { vertical velocity (section } 2 \mathrm{~d} \text { ) }\end{array}$ \\
\hline$r_{s}$ & Vertical shear dissipation rate (section $2 \mathrm{~d}$ ) \\
\hline$u_{L}, v_{L}, w_{L}$ & $\begin{array}{l}\text { Zonally low-pass-filtered anomalous velocity } \\
\text { (section } 2 \mathrm{e} \text { ) }\end{array}$ \\
\hline$V_{L}$ & $v_{L}$ integrated over upper $60 \mathrm{~m}$ (section $\left.3 \mathrm{c}\right)$ \\
\hline$V_{g}, w_{G}$ & Geostrophic component of $V_{L}, w_{L}$ (section 3c) \\
\hline$V_{\mathrm{AG}}, w_{\mathrm{AG}}$ & Ageostrophic component of $V_{L}, w_{l}$ (section 3c) \\
\hline
\end{tabular}

TABLE 1. Nomenclature.

$$
\left(U_{\tau}, V_{\tau}\right)=\left[\frac{r_{s} \tau_{x}^{\prime}}{\rho_{0}\left(f^{2}+r_{s}^{2}\right)}, \frac{-f \tau_{x}^{\prime}}{\rho_{0}\left(f^{2}+r_{s}^{2}\right.}\right]
$$

By construct, $\partial \tau_{x}^{\prime} / \partial x$ and $\partial \tau_{x}^{\prime} / \partial y$ are zero near the equator and along $140^{\circ} \mathrm{W}$ (section $2 \mathrm{~b}$ ) and $w_{\tau}$ reduces to

$$
w_{\tau}=\frac{\beta\left(f^{2}-r_{s}^{2}\right) \tau_{x}^{\prime}}{\rho_{0}\left(f^{2}+r_{s}^{2}\right)^{2}},
$$

which equals the meridional gradient of $V_{\tau}$ (Figs. 4c,d). For a weakened trade wind anomaly (section $2 b$ ), these modified Ekman solutions predict anomalous eastward transport, equatorial downwelling, maximum equatorward transport at $2.3^{\circ}$ latitude $\left( \pm r_{s} / \beta\right)$, and maximum off-equatorial upwelling at $4^{\circ}$ latitude $\left( \pm \sqrt{3} r_{s} / \beta\right)$ (Fig. 4). Both $V_{\tau}$ and $w_{\tau}$ (Figs. $4 \mathrm{~b}, \mathrm{c}$ ) are later used to interpret the ageostrophic response of the TCs to imposed wind anomalies. Model statistics will also be used to test the choice of $r_{s}$.

\section{e. Zonal filtering of TIWs}

Changes to the meridional shear of the zonal currents in response to the zonal wind anomalies produce very large modifications to the amplitude and other characteristics of the TIW velocity fluctuations. These changes obscure the relatively small linear wind-driven response. Temporal filtering can be applied to remove the TIWs (as in section 2d), but this would smooth the temporal signature of the wind-driven response in these short 61-day experiments. Instead, zonal filtering is used to separate the two signals. This approach was recently applied by Seo et al. (2007) to remove signals with zonal scales larger than $10^{\circ}$ longitude and isolate 
$\mathrm{U}_{\tau}$

a)

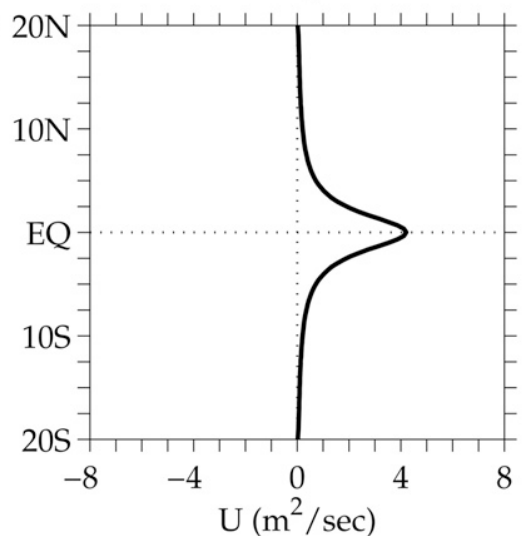

C)

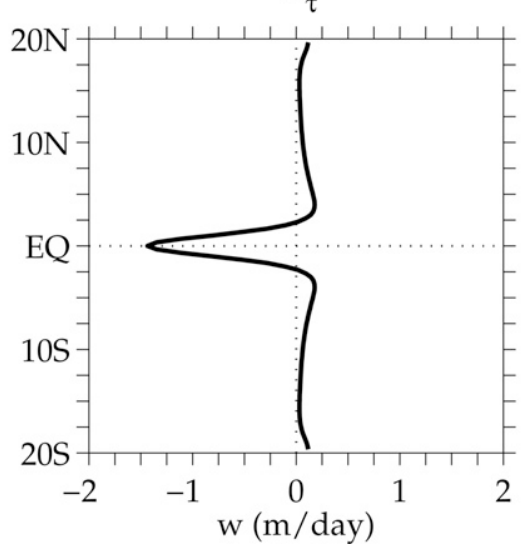

b)

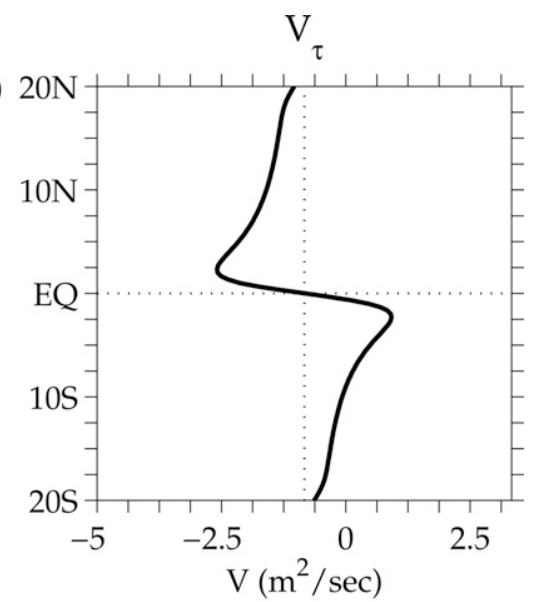

d)

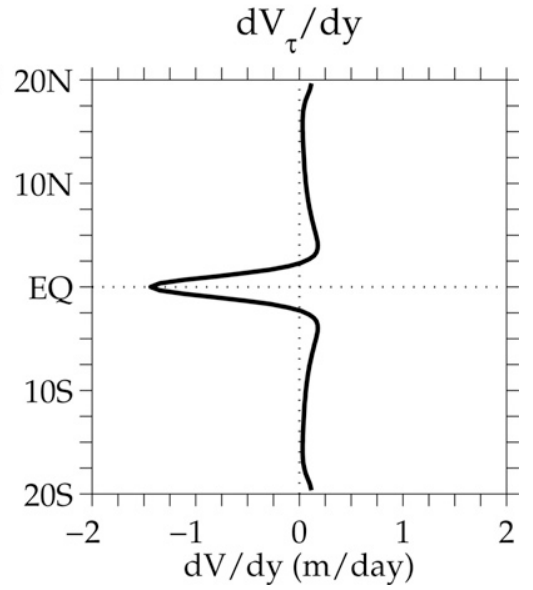

FIG. 4. Equatorially modified Ekman zonal and meridional transport $\left(U_{\tau}, V_{\tau}\right)$ for the weakened trade wind anomaly. Ekman vertical velocity computed from the depth-integrated continuity equation using full transport $\left(w_{\tau}\right)$ and meridional transport $\left(\partial V_{\tau} / \partial y\right)$.

TIWs in a model. The zonal wavelengths of the model TIWs range between $8^{\circ}$ and $12^{\circ}$ longitude and the nominal width of the wind patch is $15^{\circ}$, so a $15^{\circ}$ zonal low-pass triangle filter is used to isolate the large-zonalscale response to anomalous winds. The subscript $L$ indicates zonally low-pass filtered fields (e.g., $u_{L}$ ).

\section{Weakened trade winds results}

\section{a. Near-surface response}

\section{1) SPRING/SUMMER}

The model's near-surface background circulation ( $u_{\text {clim }}, v_{\text {clim }}$ at 5-m and $w_{\text {clim }}$ at 60-m depth) averaged over 45 days (section 2b) in spring/summer is shown in Fig. 5. At this time of year, the southeasterly trade winds are weak (Figs. 3a,b) and seasonally the model EUC has shoaled, giving eastward surface flow along the equator (Fig. 5a). Relatively weak meridional shear between the SECN and NECC characterize the flow along $140^{\circ} \mathrm{W}$, consistent with weak TIWs at this time of year. The meridional structure of poleward flow in spring/summer (Fig. 5b) is more symmetric than the annual mean (Fig. 1c) with northward flow north of the equator only $8 \mathrm{~cm} \mathrm{~s}^{-1}$ faster than the analogous southward flow south of the equator when $v_{\text {clim }}$ is averaged over the wind patch (dashed lines in Fig. 5 indicate the approximate zonal boundaries of the full-amplitude anomalous winds). Equatorial upwelling between $2.5^{\circ} \mathrm{S}$ and $2.5^{\circ} \mathrm{N}$ is also weaker than the annual mean (cf. Figs. $5 \mathrm{c}$ and $1 \mathrm{e}$ ), and there is nearly symmetric off-equatorial downwelling $\left(-0.5 \mathrm{~m} \mathrm{day}^{-1}\right.$ at $4.3^{\circ} \mathrm{S}$ and $-0.9 \mathrm{~m} \mathrm{day}^{-1}$ at $3.3^{\circ} \mathrm{N}$ averaged over the wind patch).

Not surprisingly, when forced with weakened trade winds, all elements of the large-scale (zonally low-pass filtered) circulation slow down (Fig. 6). As seen in the 45-day mean of $u_{L}$ at $5 \mathrm{~m}$ (Fig. 6a), the direct ocean response is an eastward near-surface anomaly. The 
a)

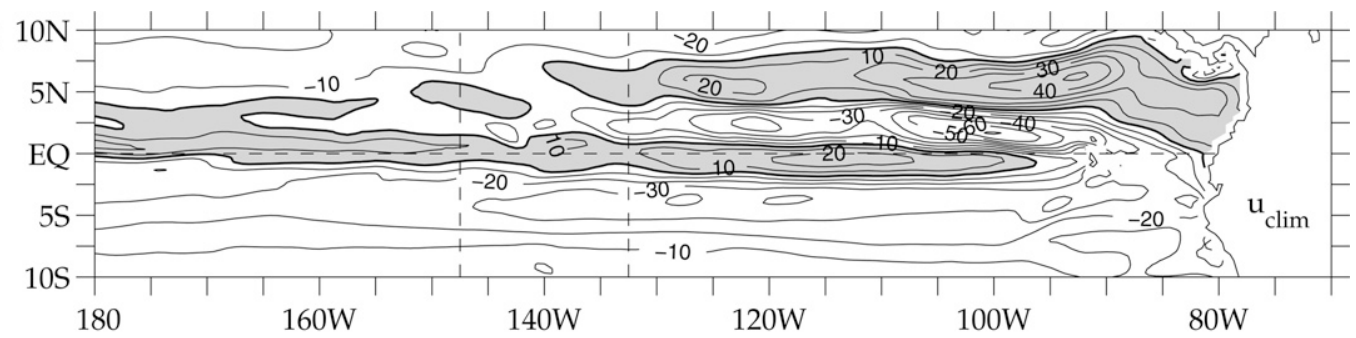

b)

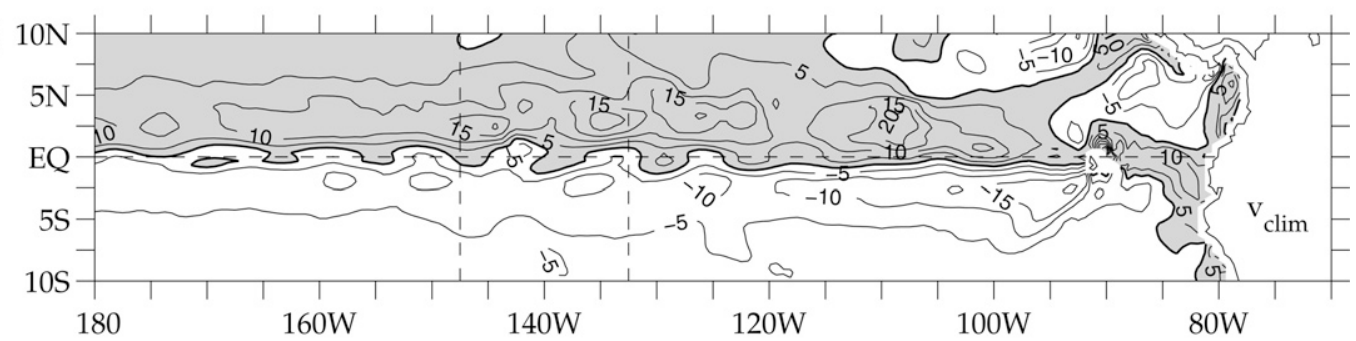

c)

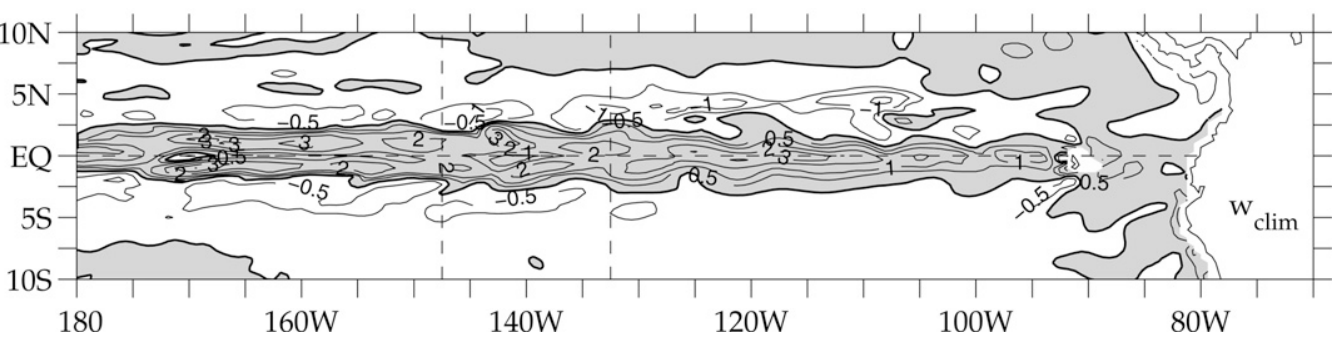

FIG. 5. The 45-day-mean circulation from climatological control run during spring/summer. Horizontal velocity shown at 5-m depth and vertical velocity at 60-m depth. Contour intervals for mean (a) $u_{\text {clim }}$, (b) $v_{\text {clim }}$, and (c) $w_{\text {clim }}$ are $10 \mathrm{~cm} \mathrm{~s}^{-1}, 5 \mathrm{~cm} \mathrm{~s}^{-1}$, and $1 \mathrm{~m} \mathrm{day}^{-1}$ (with addition of $\pm 0.5 \mathrm{~m} \mathrm{day}^{-1}$ contour), respectively. Thick solid line corresponds to zero contour and shaded contours indicate positive values.

shoaled EUC is strengthened, both branches of the SEC are weakened off the equator, and the meridional shear between the SECN and NECC is decreased. The zonal velocity anomaly propagates eastward as a Kelvin wave and affects the eastern equatorial Pacific from the eastern boundary of the wind patch to the Galapagos Islands. This anomalous Kelvin wave only carries modifications to zonal velocity.

Under the wind patch, the imposed westerly wind anomaly forces anomalous near-surface equatorward flow at $5 \mathrm{~m}$ (Fig. 6b), which reduces the strength of the background TCs (Fig. 5b). This drives anomalous equatorial downwelling and off-equatorial upwelling with maxima between $3^{\circ}$ and $4^{\circ}$ latitude at $60 \mathrm{~m}$ (Fig. 6c). Although the magnitude of the anomalous velocities are slightly stronger north of the equator, the latitudinal structure of the anomalies is nearly symmetric (for $u_{L}, w_{L}$ ) or antisymmetric (for $v_{L}$ ) along $140^{\circ} \mathrm{W}$.

TIWs are seasonally weak during this time period. Weakening the trade winds further decreases the TIW velocity amplitudes and reduces westward propagation speeds by up to $2 \mathrm{~cm} \mathrm{~s}^{-1}$, which adjusts the locations of the TIW crests and troughs (not shown). Smaller TIW amplitudes are consistent with the reduced meridional shear of the zonal currents (Fig. 6a), and the slow down of TIW propagation is consistent with the weakened SECN (Lyman 2002). During this period, the anomalous TIW variance (short-scale variability removed by the low-pass filter in section 2e) north of the equator and east of the wind patch is weak. As a result, the nonlinear rectification by the TIWs on the anomalous TCs is negligible in spring/summer [i.e., $\left(v_{L}, w_{L}\right)$ are minimally asymmetric under the wind path and near zero east of the wind patch].

\section{2) FALL}

During fall, the 45-day-mean background circulation is driven by seasonally strong southeasterly trade winds (Figs. 3a,b). The SEC and NECC are both near their annual peaks, with the SEC dominating the surface zonal flow from $10^{\circ} \mathrm{S}$ to $4.9^{\circ} \mathrm{N}$ (Fig. 7a). At this time of year the meridional shear of $u_{\text {clim }}$ is large in the central Pacific. This shear produces vigorous TIWs, predominantly north of the equator. The TCs in fall (Figs. 7b,c) are more asymmetric than the annual mean (Figs. 1c,e) with a band of northward surface flow north of the 
a)

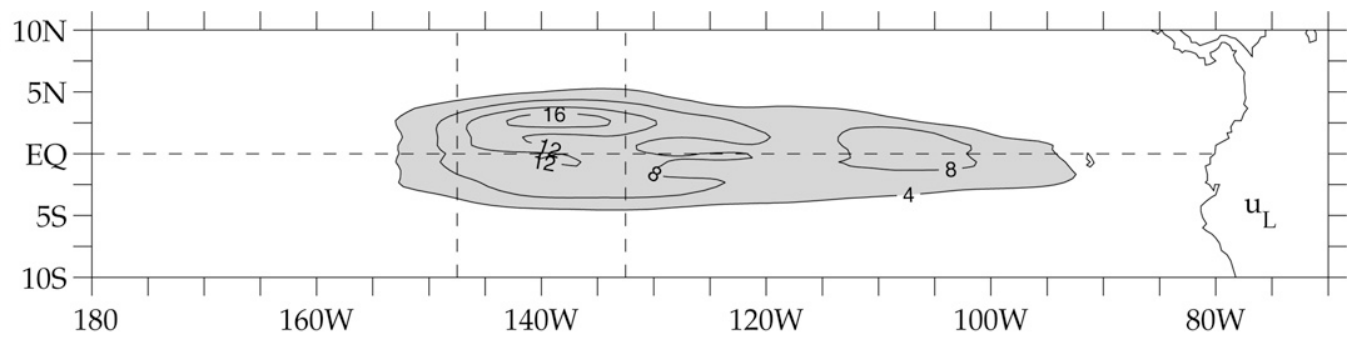

b)

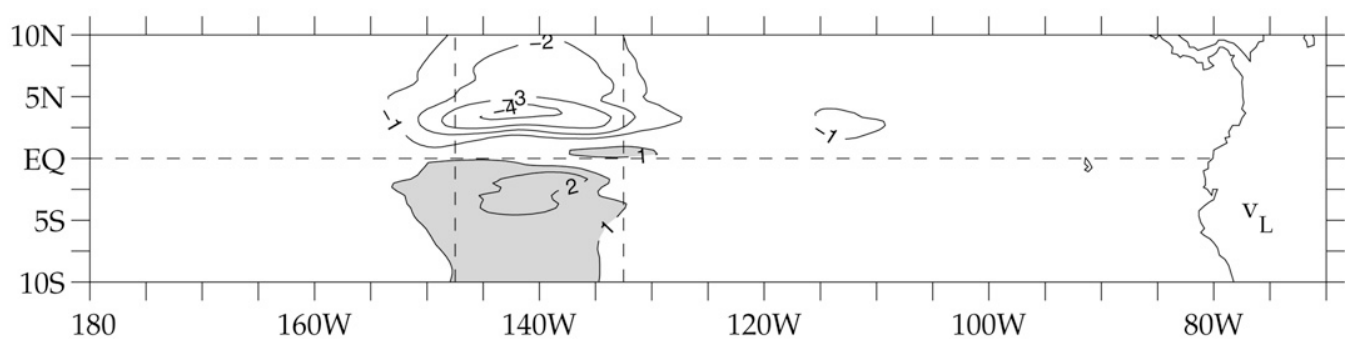

c)

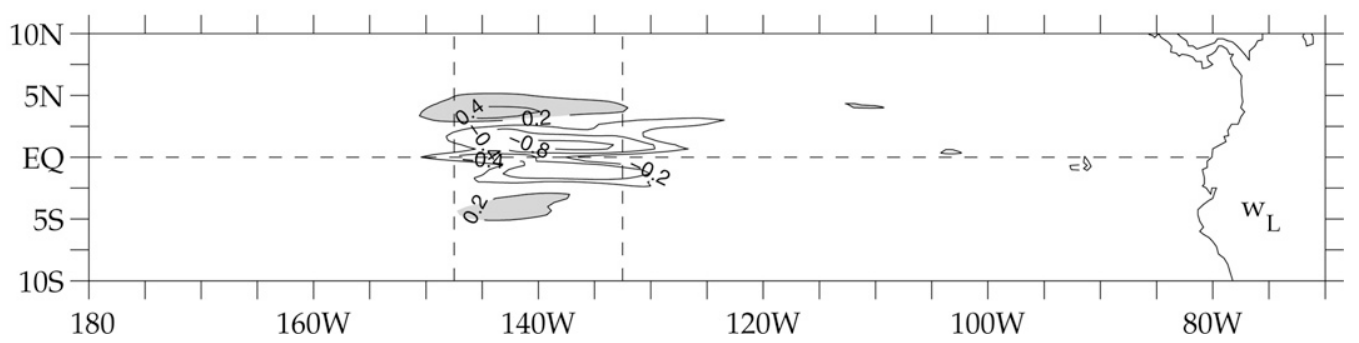

FIG. 6. The 45-day-mean zonally low-pass-filtered circulation from weakened trade wind run minus the control circulation during spring/summer. Horizontal velocity shown at 5-m depth and vertical velocity at $60-\mathrm{m}$ depth. Contour intervals for mean (a) $u_{L}$, (b) $v_{L}$, and (c) $w_{L}$ are $4 \mathrm{~cm} \mathrm{~s}^{-1}, 1 \mathrm{~cm} \mathrm{~s}^{-1}$, and $0.4 \mathrm{~m} \mathrm{day}^{-1}$ (with addition of $\pm 0.2 \mathrm{~m}$ day $^{-1}$ contour), respectively. Shaded contours indicate positive values. The zero contour is not plotted.

equator that is twice as fast as the analogous southward flow south of the equator, resulting in a sharp narrow band of off-equatorial downwelling $\left(-2.3 \mathrm{~m} \mathrm{day}^{-1}\right.$ near $3.5^{\circ} \mathrm{N}$ averaged over the wind patch). Some of this equatorial asymmetry arises from the linear winddriven response to the stronger trade winds (Figs. 3c,d). Additional asymmetry can be due to nonlinear advection, which includes a large-zonal-scale contribution (associated with stronger background TCs) and a smallzonal-scale contribution (associated with stronger background TIWs), as well as linear processes not included in the equatorially modified Ekman model. Nonlinear rectification by the TIWs onto the TCs comes from this small-zonal-scale nonlinear advection term in the momentum balance.

Because the same anomalous winds are imposed in both seasons, differences in the response of the TCs between fall and spring/summer should be due to nonlinearities. Under the wind patch, these differences are due to both the stronger background TCs and TIWs. East of the wind patch, the anomalous winds are near zero. Therefore, differences in the anomalous TCs east of the wind patch are due to TIWs modified by the altered zonal currents carried by the eastward propagating Kelvin wave [section 3a(1)].

As in the spring/summer experiment, weakening the trade winds produces an eastward anomaly and reduces the strength of the background TCs under the wind patch (Fig. 8). However, unlike the earlier case, the equatorial asymmetry of $v_{L}$ and $w_{L}$ has dramatically increased with much stronger equatorward flow north of the equator (Fig. 8b) and a strong narrow band of anomalous upwelling near $4.5^{\circ} \mathrm{N}$ (Fig. 8c). In and east of the patch, there is anomalous northward flow between the equator and $2^{\circ} \mathrm{N}$ (Fig. 8b). East of the patch, there is anomalous southward flow between the $2^{\circ} \mathrm{S}$ and the equator (Fig. 8b). The meridional divergence/ convergence associated with the complex structure of $v_{L}$ produces additional upwelling/downwelling anomalies that extend well east of the wind anomaly (Fig. 8c).

As in spring/summer, weakening the trade winds weakens TIW amplitudes, reduces the phase speeds, and shifts the locations of the crests and troughs (not shown). In fall, however, the background TIWs are seasonally strong, and the anomalous TIW velocity fluctuations are up to a factor of 4 larger. The anomalous 
a)

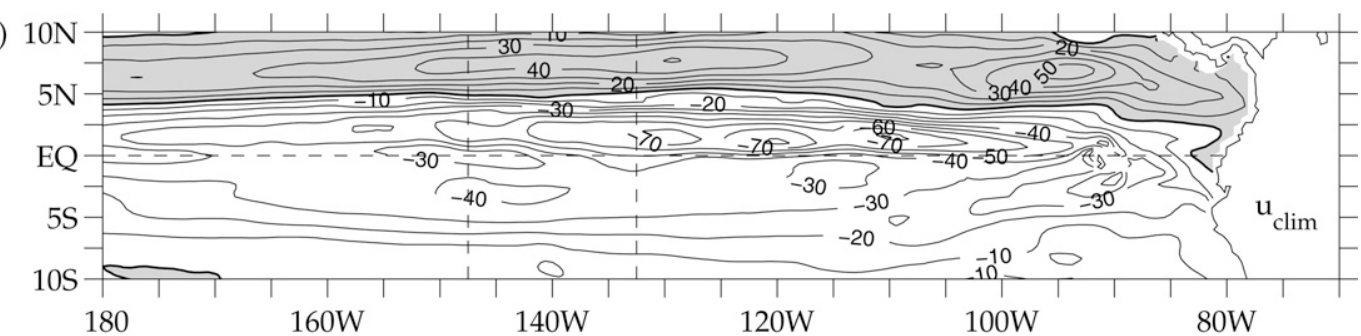

b)

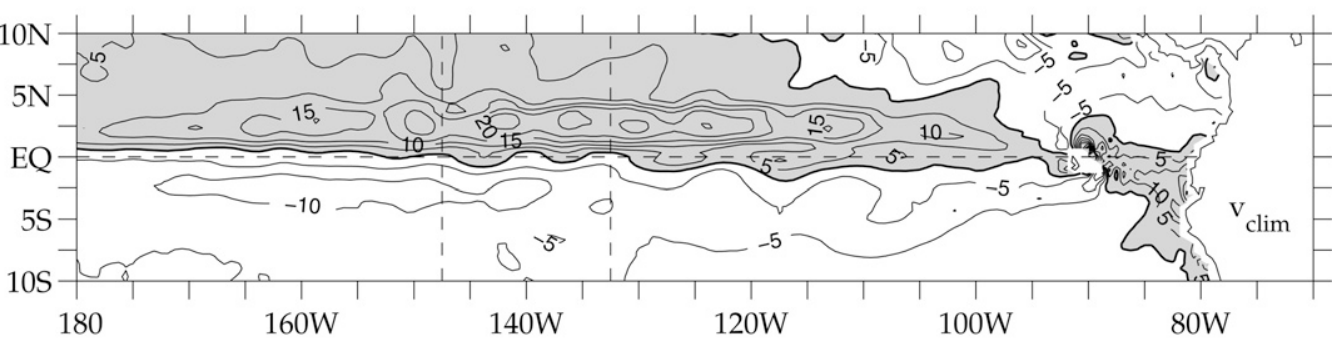

c)

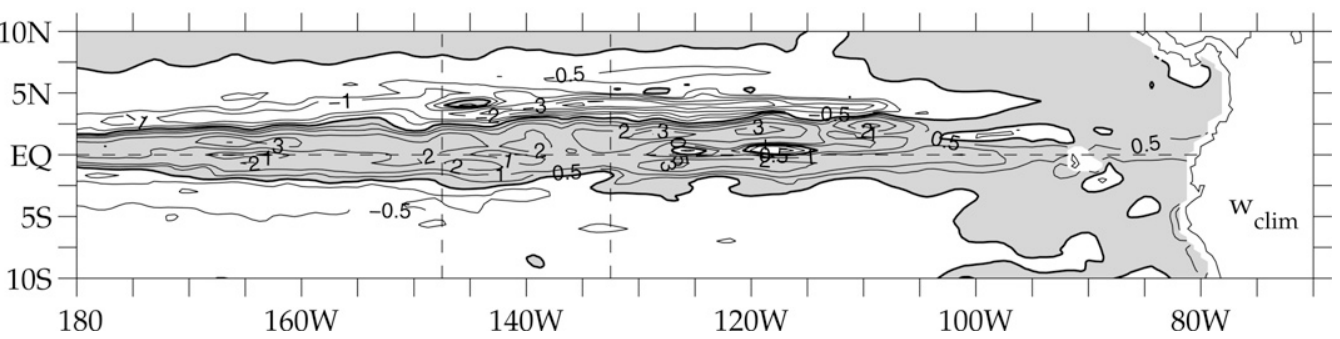

FIG. 7. The 45-day-mean circulation from climatological control run during fall. Horizontal velocity shown at 5-m depth and vertical velocity at 60-m depth. Contour intervals for mean (a) $u_{\text {clim }}$, (b) $v_{\text {clim }}$, and (c) $w_{\text {clim }}$ are $10 \mathrm{~cm} \mathrm{~s}^{-1}$, $5 \mathrm{~cm} \mathrm{~s}^{-1}$, and $1 \mathrm{~m} \mathrm{day}^{-1}$ (with addition of $\pm 0.5 \mathrm{~m} \mathrm{day}^{-1}$ contour), respectively. Thick solid line corresponds to zero contour and shaded contours indicate positive values.

TIW variance is largest north of the equator in and east of the wind patch, coinciding with locations where the anomalous TCs in fall and spring/summer differ (cf. Figs. 6b,c, 8b,c) and providing further evidence of TIW rectification.

\section{b. Vertical structure of the response along $140^{\circ} \mathrm{W}$}

In the previous section, the near-surface anomalous circulation was described in and east of the wind patch (Figs. 6, 8). The zonal low-pass filter has removed short zonal scales, so the response along $140^{\circ} \mathrm{W}$ is representative of the response in the wind patch region. In this section, the vertical extent of the anomalous response is examined through $y z$ sections of the 45-day mean along $140^{\circ} \mathrm{W}$.

\section{1) SPRING/SUMMER}

In spring/summer, the mean $u_{L}$ is eastward in the upper $100 \mathrm{~m}$ across the wave guide as the anomalous winds weaken the SEC (with stronger modification to the SECN) and increase the strength of the EUC near the surface (Fig. 9a). Weakening the trade winds also reduces the zonal pressure gradient, which weakens the strength of the EUC core by about $8 \mathrm{~cm} \mathrm{~s}^{-1}$ (small westward anomaly at $105 \mathrm{~m}$ in Fig. 9a). All elements of the TCs decrease (Figs. 9b,c,d). The surface limb of the anomalous TCs spans the upper $60 \mathrm{~m}$ of the water column. Below $60 \mathrm{~m}$, the anomalous poleward flow is nearly antisymmetric about the equator (Fig. 9b) and counters the background geostrophic convergence (Fig. 1c). The equatorial downwelling anomaly (maximum at $90 \mathrm{~m}$ and at $1^{\circ} \mathrm{N}, 60 \mathrm{~m}$ ) extends to $200 \mathrm{~m}$ (Fig. 9c) and decreases the strength of the background equatorial upwelling (Fig. 1e). Nearly symmetric anomalous offequatorial upwelling with maxima at $3.3^{\circ} \mathrm{S}, 60 \mathrm{~m}$ and $3.7^{\circ} \mathrm{N}, 60 \mathrm{~m}$ opposes the background off-equatorial downwelling.

\section{2) FALL}

In contrast to the spring/summer, there is significant equatorial asymmetry throughout the upper $150 \mathrm{~m}$ during fall (Fig. 10). Modifications to the anomalous TCs are considerably larger north of the equator in fall, with relatively little interseasonal difference south of the equator (cf. Figs. 9b,c,d and 10b,c,d). The sharp divergence of $v_{L}$ at $4^{\circ} \mathrm{N}$ drives anomalous off-equatorial 
a)

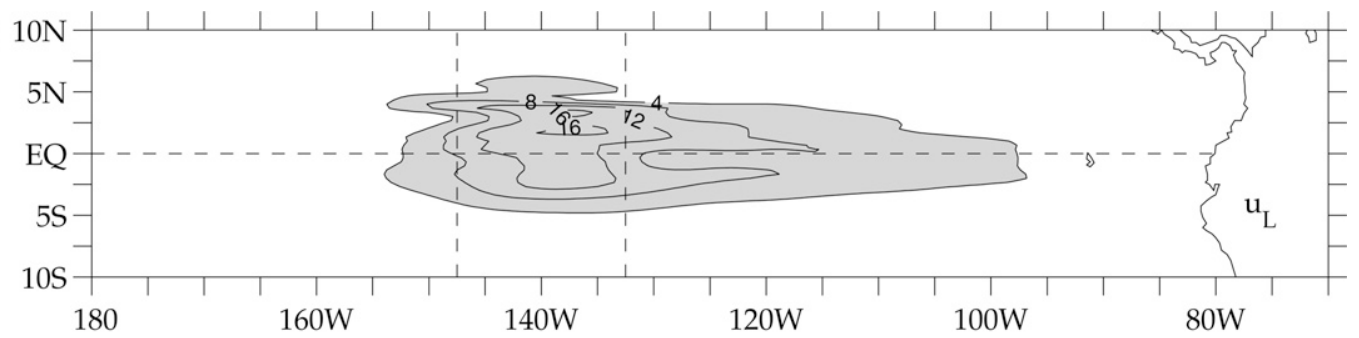

b)

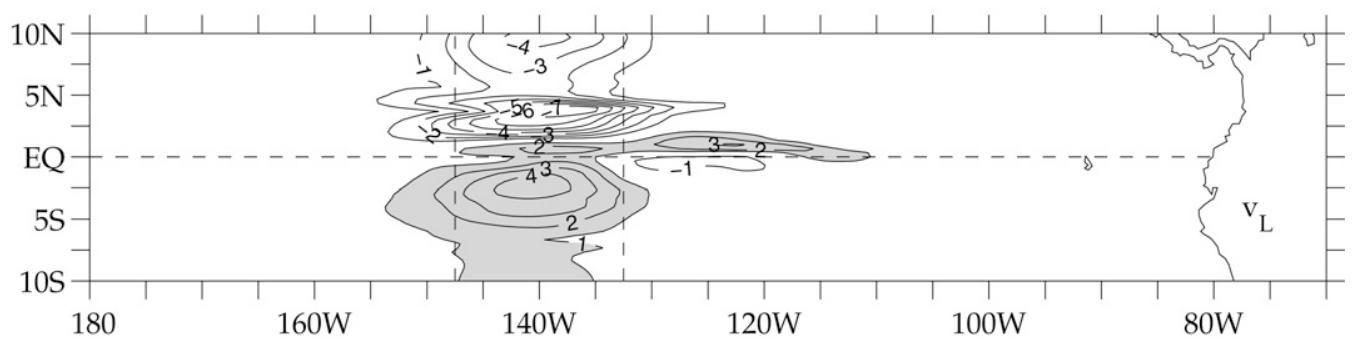

c)

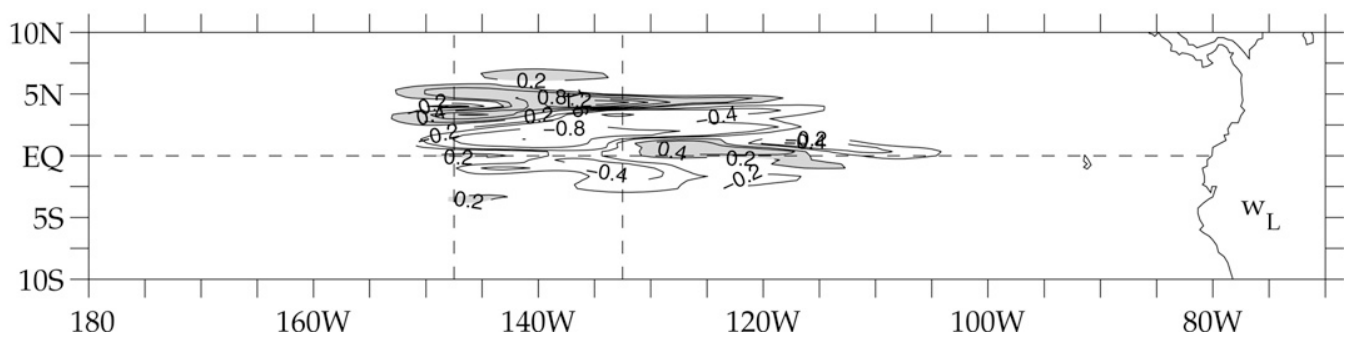

FIG. 8. The 45-day-mean zonally low-pass-filtered circulation from weakened trade wind run minus the control circulation during fall. Horizontal velocity shown at 5-m depth and vertical velocity at $60-\mathrm{m}$ depth. Contour intervals for mean (a) $u_{L}$, (b) $v_{L}$, and (c) $w_{L}$ are $4 \mathrm{~cm} \mathrm{~s}^{-1}, 1 \mathrm{~cm} \mathrm{~s}^{-1}$, and $0.4 \mathrm{~m} \mathrm{day}^{-1}$ (with addition of $\pm 0.2 \mathrm{~m} \mathrm{day}^{-1}$ contour), respectively. Shaded contours indicate positive values. The zero contour is not plotted.

upwelling of more than $1 \mathrm{~m}^{\text {day }}{ }^{-1}$ at 70 -m depth (Fig. 10c). Although the vertical extent of the surface limb of the anomalous TCs is about $10 \mathrm{~m}$ deeper in the fall, the surface response principally occurs in the upper $60 \mathrm{~m}$ of the water column.

\section{c. Geostrophic and ageostrophic response along $140^{\circ} \mathrm{W}$}

As the surface limb of the TCs is largely contained within the upper $60 \mathrm{~m}$ of the water column (section $3 \mathrm{~b}$ ), the zonally low-pass filtered meridional transport integrated over the upper $60 \mathrm{~m}\left(V_{L}\right)$ is a good index of the near-surface anomalous response along $140^{\circ} \mathrm{W}$. This transport is separated into anomalous geostrophic transport $\left(V_{G}\right)$ and ageostrophic transport $\left(V_{\mathrm{AG}}\right)$ by vertically integrating and zonally filtering geostrophic and ageostrophic currents (section 2). From continuity, $w_{L}$ at $60 \mathrm{~m}$ can also be separated into a geostrophic component $\left(w_{G}\right)$ and an ageostrophic component $\left(w_{\mathrm{AG}}\right)$. This separation allows comparison of the meridional and temporal structure of the ageostrophic response in the surface limb of the TCs with the meridional structure of the linear equatorially modified Ekman solutions
(Figs. 4b,c) and temporal evolution of the westerly wind anomaly (Fig. 2).

\section{1) SPRING/SUMMER}

In spring/summer, the relatively large 45-day-mean ageostrophic response exceeds the opposing geostrophic response in the upper $60 \mathrm{~m}$ (Figs. 11a,b). As seen in previous sections, the total response $\left(V_{L}, w_{L}\right)$ spins down the surface limb of the background TCs. The structure of $V_{\mathrm{AG}}$ is very similar to $V_{\tau}$ (Fig. 11a), except the extrema at $2.3^{\circ} \mathrm{S}$ and $3.0^{\circ} \mathrm{N}$ (circles) are larger and slightly asymmetric (ratio of the magnitude of the northern minimum of $V_{\mathrm{AG}}$ to that of the southern maximum is 1.08). Similarly, $w_{\mathrm{AG}}$ compares well with $w_{\tau}$ (Fig. 11b) with strong anomalous downwelling along the equator between $2.5^{\circ} \mathrm{S}$ and $2.7^{\circ} \mathrm{N}$ and nearly symmetric anomalous upwelling with maxima at $3.3^{\circ} \mathrm{S}$ and $3.7^{\circ} \mathrm{N}$. The broad bands of downwelling/upwelling are dominated by the convergence/divergence of meridional transport alone (Figs. 11b,c). As a result, the off-equatorial extrema of $w_{\mathrm{AG}}\left(\partial w_{\mathrm{AG}} / \partial y=0\right)$ coincide with the inflection points of $V_{\mathrm{AG}}\left(\partial^{2} V_{\mathrm{AG}} / \partial y^{2}=0\right)$ at 

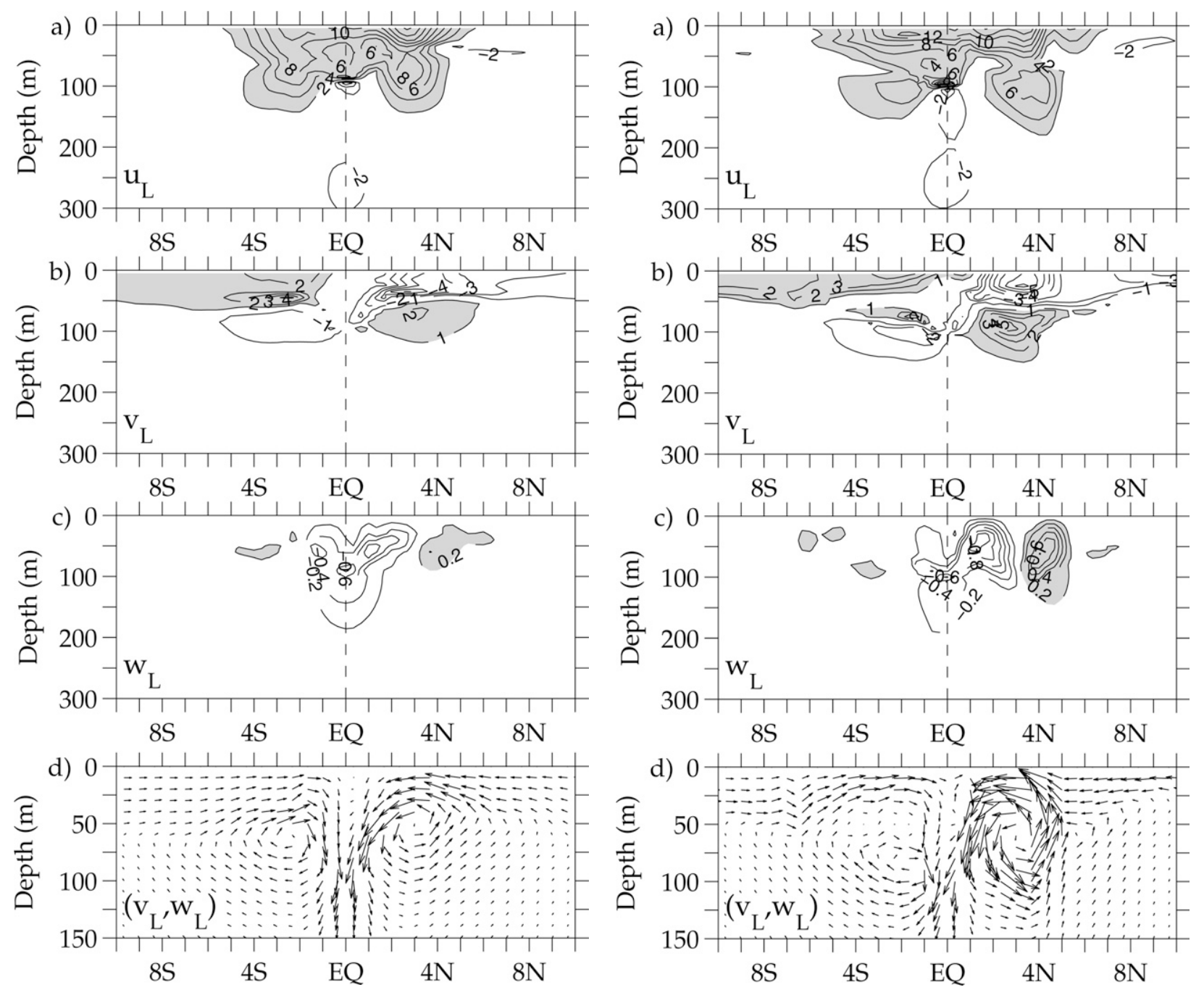

FIG. 9. The 45-day mean $\left(u_{L}, v_{L}, w_{L}\right)$ along $140^{\circ} \mathrm{W}$ during spring/summer. Contour intervals for mean (a) $u_{L}$, (b) $v_{L}$, and (c) $w_{L}$ are $2 \mathrm{~cm} \mathrm{~s}^{-1}, 1 \mathrm{~cm} \mathrm{~s}^{-1}$, and $0.2 \mathrm{~m} \mathrm{day}^{-1}$, respectively. Shaded contours indicate positive values. The zero contour is not plotted. Scaled vectors depict the anomalous TCs in the upper $150 \mathrm{~m}$.

$3.3^{\circ} \mathrm{S}$ and $3.7^{\circ} \mathrm{N}$ (diamonds). The extrema and inflection points will be revisited in section $4 \mathrm{~b}$ as a means to define the transition from an equatorial to Ekman dynamical response.

Empirical orthogonal function analysis is used to diagnose both the meridional and temporal structures of the anomalous ageostrophic TCs during the first 31 days of the spring/summer experiment. The first EOF mode of $V_{\mathrm{AG}}$ and $w_{\mathrm{AG}}$, which represents a large fraction of the total variance $(94.1 \%$ and $66.4 \%$, respectively), can be fully understood in terms of the linear equatorially modified Ekman response to weakened trade winds. The latitudinal structures of the first EOF mode of $V_{\mathrm{AG}}$ and $w_{\mathrm{AG}}$ (Figs. 12a,b) are similar to the

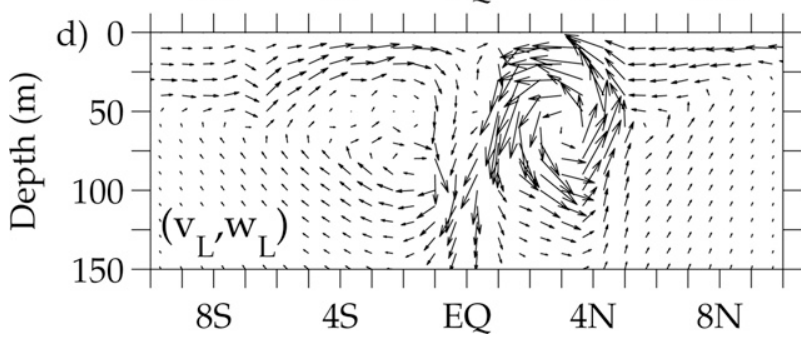

FIG. 10. The 45-day mean $\left(u_{L}, v_{L}, w_{L}\right)$ along $140^{\circ} \mathrm{W}$ during fall. Contour intervals for mean (a) $u_{L}$, (b) $v_{L}$, and (c) $w_{L}$ are $2 \mathrm{~cm} \mathrm{~s}^{-1}$, $1 \mathrm{~cm} \mathrm{~s}^{-1}$, and $0.2 \mathrm{~m} \mathrm{day}^{-1}$, respectively. Shaded contours indicate positive values. The zero contour is not plotted. Scaled vectors depict the anomalous TCs in the upper $150 \mathrm{~m}$.

structures of $\left(V_{\tau}, w_{\tau}\right)$, as well as the 45-day means (Figs. 11a,b). In addition, the first EOF principle component time series of $V_{\mathrm{AG}}$ and $w_{\mathrm{AG}}$ closely match the time evolution of the westerly wind anomaly with lags of less than a day (Fig. 12c). Note that the principal component time series by construct have zero time integrals but have been shifted such that the plotted amplitudes are zero on the first day of the experiment (i.e., the amplitude at $t=0$ is subtracted from the entire time series).

\section{2) FALL}

Although the 45-day-mean geostrophic response in fall is similar to the spring/summer response, the mean 
$\mathrm{V}$

a)

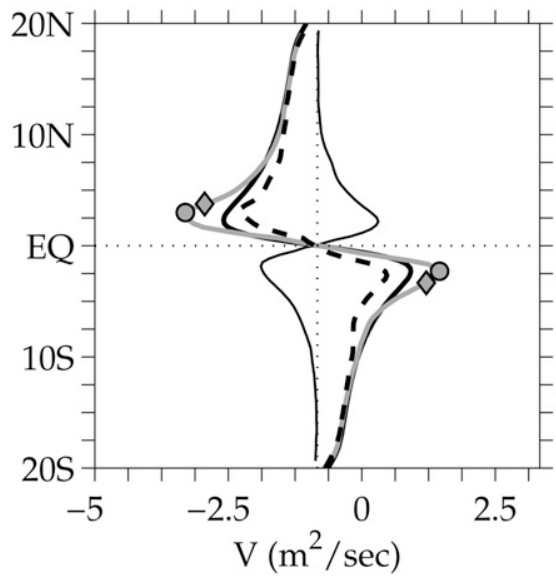

b)

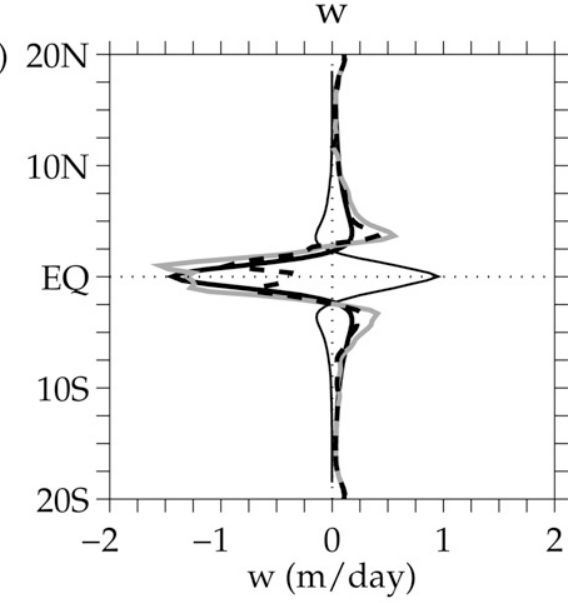

$\mathrm{dV} / \mathrm{dy}$

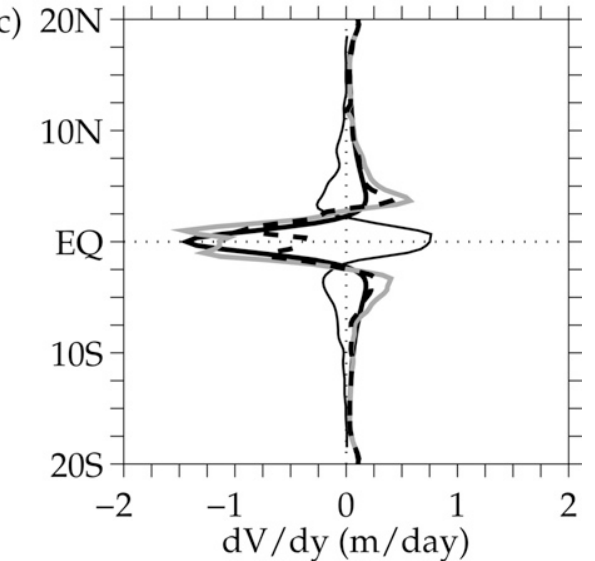

FIG. 11. Weakened trade wind run minus the control run during spring/summer along $140^{\circ} \mathrm{W}$. The 45-day-mean depth-integrated meridional transport over (a) upper $60 \mathrm{~m}(V)$, and (b) $w$ and (c) $\partial V / \partial y$ at $60 \mathrm{~m}$. Zonally low-pass-filtered anomalies (dashed lines) are separated into geostrophic (thin black lines) and ageostrophic (gray lines) components and compared with equatorially modified Ekman curves (thick black lines) from Fig. 4. Gray circles (diamonds) show extrema (inflection points) of mean $V_{\mathrm{AG}}$.

ageostrophic response is equatorially asymmetric in fall (cf. Figs. 11a,b and Figs. 13a,b). South of the equator, $V_{\text {AG }}$ is very similar to $V_{\tau}$ (Fig. 13a) and the spring/ summer experiment (Fig. 11a) with maximum and inflection point at $2.3^{\circ}$ and $3.3^{\circ} \mathrm{S}$, respectively. North of the equator, however, the magnitude of the northern minimum is much larger than that of the southern maximum (ratio of 1.84), and both the northern minimum and inflection point have shifted poleward to $3.3^{\circ}$ and $4.3^{\circ} \mathrm{N}$, respectively. As before, $w_{\mathrm{AG}}$ is dominated by $\partial V_{\mathrm{AG}} / \partial y$, so the equatorially asymmetric divergence in $V_{\text {AG }}$ produces a sharp upwelling peak at $4.3^{\circ} \mathrm{N}$ that has no counterpart in the south (Figs. 13b,c).

The latitudinal structures of the first EOF mode of $V_{\mathrm{AG}}$ and $w_{\mathrm{AG}}$ (Figs. 14a,b) are more asymmetric than the 45-day means (Figs. 13a,b). The sharp peak in $w_{\mathrm{AG}}$ near $4^{\circ} \mathrm{N}$ (Fig. 14b) narrows and increases in amplitude when EOFs are computed from the full 61-day record (not shown). This is due to rectification by the anomalous TIWs, which become more energetic in the second month of the experiment. The $V_{\mathrm{AG}}$ principal component time series closely matches the evolution of the anomalous winds with only a one day lag. In contrast, $w_{\text {AG }}$ lags the anomalous winds by 16 days and cannot be fully understood in terms of the linear equatorially modified Ekman response to weakened trade winds. The differences in the temporal evolution and meridional structure of $V_{\mathrm{AG}}$ and $w_{\mathrm{AG}}$ in spring/summer and fall (cf. Figs. 12 and 14) lead us to explore the linearity of the ageostrophic response in section 4 . 

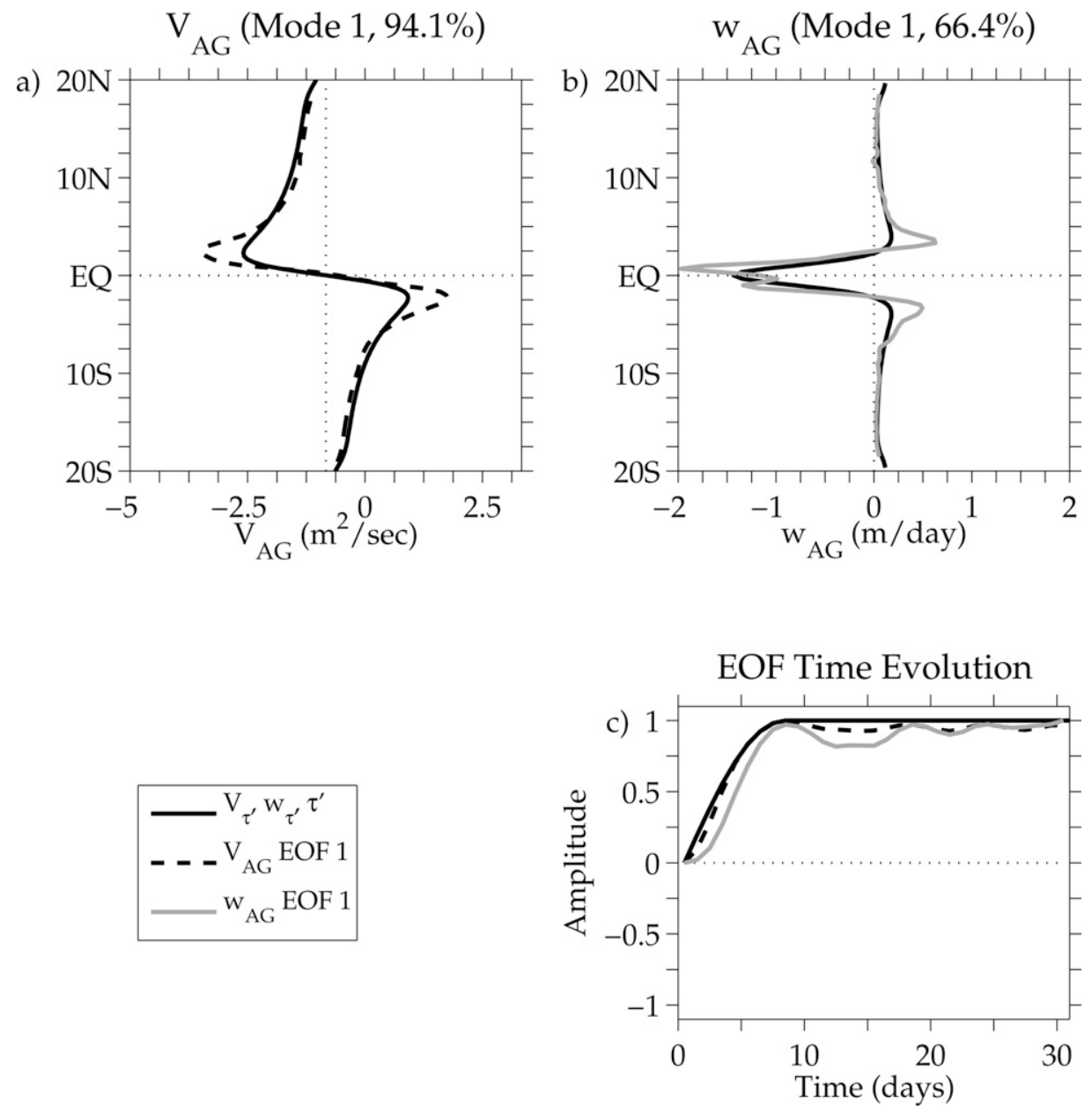

FIG. 12. First EOF mode structure for (a) $V_{\mathrm{AG}}$ (dashed line) and (b) $w_{\mathrm{AG}}$ (gray line) along $140^{\circ} \mathrm{W}$ from weakened trade wind run minus the control run during spring/summer. Percentage variance represented by first EOF provided on each panel. Thick black lines indicate corresponding equatorially modified Ekman curves from Fig. 4. (c) Temporal evolution of the weakened trade wind anomaly (thick black line) is plotted with the principal component time series of $V_{\mathrm{AG}}$ and $w_{\mathrm{AG}}$.

\section{Linearity of the ageostrophic response}

\section{a. First EOF mode}

In this section, the linearity of the anomalous ageostrophic TCs is analyzed by comparing the first-mode EOFs from strengthened trade wind experiments to those of the weakened trade wind experiments (section $3 \mathrm{c}$ ). The strengthened trade wind (or easterly wind) anomaly is identical to the westerly wind anomaly described in section $2 b$, differing only in sign. Results from winter experiments are also included to compare the situation as the background TCs and TIWs are weakening.

Figure 15 compares the first-mode EOFs of $V_{\mathrm{AG}}$ for the strengthened trades case (blue line) and weakened trade wind case (red line) during three different seasons: spring/summer, fall, and winter. For all six experi- ments, the first-mode EOFs represent more than $82 \%$ of the total variance, and the principal component time series are highly correlated with the wind anomaly time series (zero-lag correlation is greater than 0.97 ). Within a given season, the response of $V_{\mathrm{AG}}$ to anomalous winds of opposing sign is nearly identical (e.g., the structures overlap in Figs. 15a,c,e and the time series are mirror images in Figs. 15b,d,f). The largest differences in the $V_{\mathrm{AG}}$ first EOF structures occur between seasons (cf. Figs. 15a and 15c,e). In particular, there is enhanced equatorial asymmetry and large deviations from the $V_{\tau}$ solution north of the equator in fall and winter.

The response of $w_{\text {AG }}$ first EOF mode to anomalous winds of opposing sign is more complex (Fig. 16). In spring/summer (Figs. 16a,b), the structures for strengthened and weakened winds are nearly identical and represent 
$\mathrm{V}$

a)

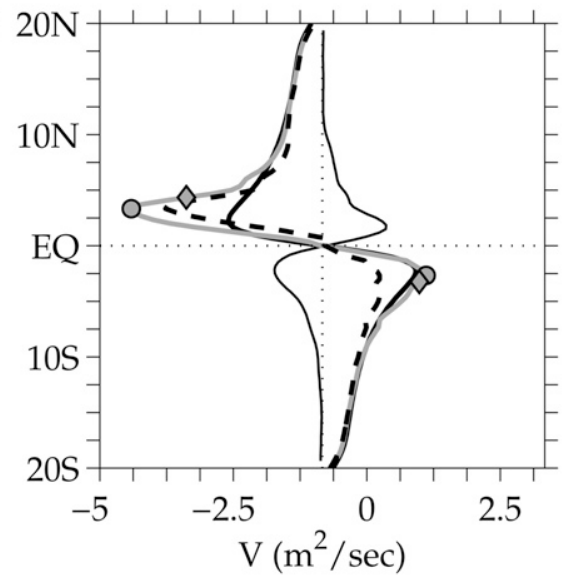

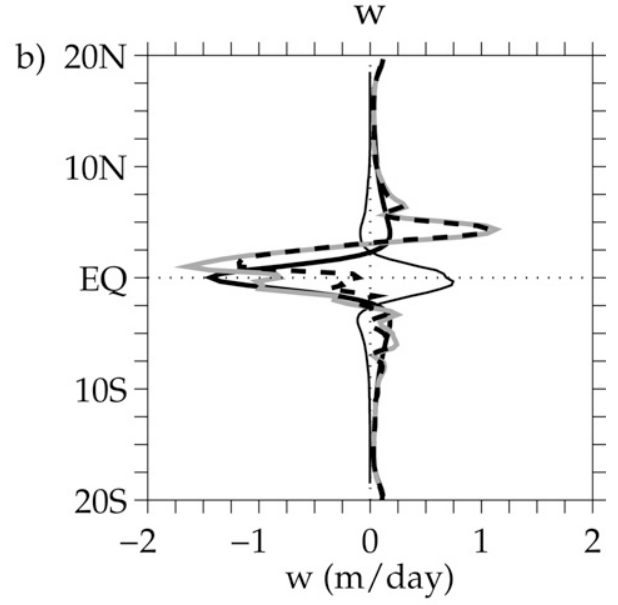

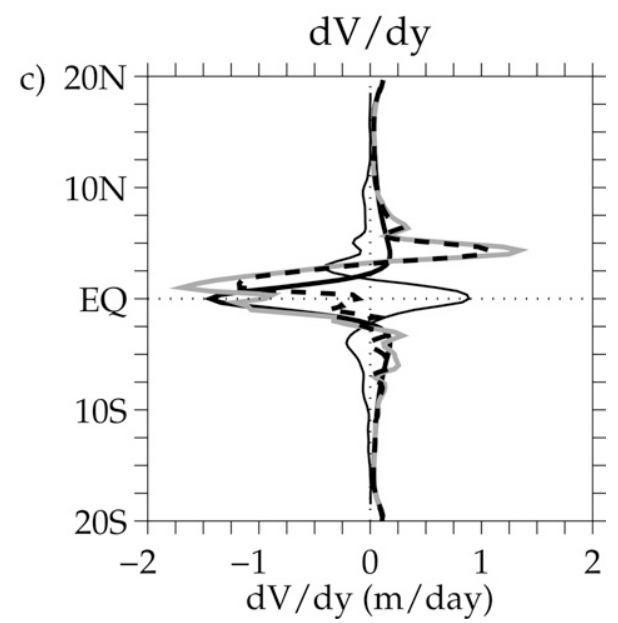

FIG. 13. Weakened trade wind run minus the control run during fall along $140^{\circ} \mathrm{W}$. The 45 -day-mean depth-integrated meridional transport over (a) upper $60 \mathrm{~m}(V)$, and (b) $w$ and (c) $\partial V / \partial y$ at $60 \mathrm{~m}$. Zonally low-pass-filtered anomalies (dashed lines) are separated into geostrophic (thin black lines) and ageostrophic (gray lines) components and compared with equatorially modified Ekman curves (thick black lines) from Fig. 4. Gray circles (diamonds) show extrema (inflection points) of mean $V_{\text {AG. }}$.

a large fraction of the total variance (about $67 \%$ ), and the time series are highly correlated with the wind anomaly time series (zero-lag correlation is 0.97). By contrast, fall and winter responses show upwelling and downwelling peaks with very small meridional scales that do not overlap for strengthened and weakened trades (Figs. 16c,e). The fraction of variance represented by the first mode (between $55 \%$ and $65 \%$ ) and the correlations with the wind anomaly time series $(0.35$ to 0.8 ) are also significantly smaller for these seasons (Figs. 16d,f). Given that magnitude and structure of the wind anomalies are the same for all these experiments, Figs. 15 and 16 demonstrate that the dominant mode of variability for the anomalous ageostrophic TCs can be fully understood in terms of the linear equatorially modified Ekman response in spring/summer (back- ground TCs and TIWs are weak). In fall and winter (background TCs and TIWs are strong), nonlinearities are present in the dominant mode of variability.

\section{b. Zonal wind experiment statistics}

Little is known from either theory or observations about the latitude at which the TCs transition from their equatorial structure to an Ekman-like structure. Here, the transition is defined by both the extrema of $V_{\mathrm{AG}}$, where the curve ceases growing with decreasing latitude, and by the off-equatorial inflection points of $V_{\mathrm{AG}}$, where the off-equatorial extrema of $w_{\mathrm{AG}}$ are found (section 3c). For the linear equatorially modified Ekman model with $r_{s}^{-1}=2$ day, these occur at $2.3^{\circ}$ and $4^{\circ}$ latitude, respectively, in both hemispheres (section $2 \mathrm{~d}$ ). Table 2 compiles the locations of the 45 -day-mean 

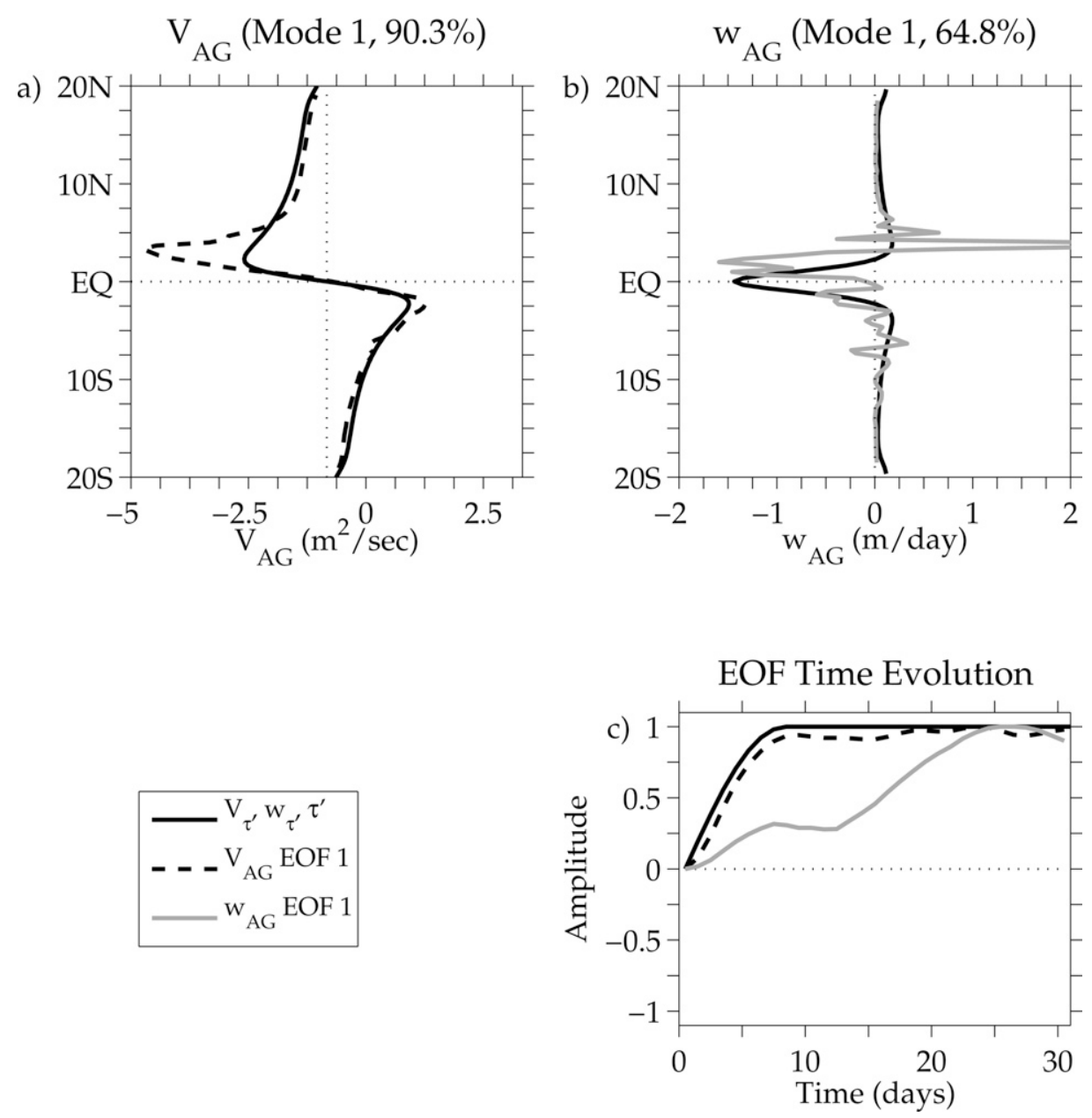

FIG. 14. First EOF mode structure for (a) $V_{\mathrm{AG}}$ (dashed line) and (b) $w_{\mathrm{AG}}$ (gray line) along $140^{\circ} \mathrm{W}$ from weakened trade wind run minus the control run during spring/summer. Percentage variance represented by first EOF provided on each panel. Thick black lines indicate corresponding equatorially modified Ekman curves from Fig. 4. (c) Temporal evolution of the weakened trade wind anomaly (thick black line) is plotted with the principal component time series of $V_{\mathrm{AG}}$ and $w_{\mathrm{AG}}$.

$V_{\mathrm{AG}}$ extrema and inflection points as well as the ratio of the magnitude of the northern extreme to southern extreme for the weakened and strengthened trade wind runs. These statistics are a convenient measure to quantify the deviations of $V_{\mathrm{AG}}$ from the linear antisymmetric $V_{\tau}$. To further elucidate the linearity of these processes, results from one-tenth magnitude versions of the weakened and strengthened trade wind runs are also included.

In general, the structure of $V_{\mathrm{AG}}$ depends more on the season than on the sign and magnitude of the imposed trade wind anomaly (Table 2). During spring/summer, the ratio of the extrema magnitudes is close to unity (i.e., antisymmetry) with average value of 1.08 , and the extrema and inflection points are relatively close to the equator. During fall and winter, on the other hand, the equatorial asymmetry is much larger. The extrema and inflection points shift poleward by $0.1^{\circ}$ to $1.6^{\circ}$ (more pronounced north of the equator) and the ratio of the extrema has increased $(1.61 \pm 0.16$ and $1.36 \pm 0.16$ in fall and winter, respectively). Note that for all seasons the distance between extrema and inflection points is less than the $1.7^{\circ}$ predicted by equatorially modified Ekman model with $r_{s}^{-1}=2$ day (section $2 \mathrm{~d}$ ).

Equations (6) and (7) for the modified Ekman model can be solved for $r_{s}^{-1}$, using the 45-day-mean values of $V_{\mathrm{AG}}$ and $w_{\mathrm{AG}}$ from each wind experiment in place of $V_{\tau}$ and $w_{\tau}$. Using $w_{\mathrm{AG}}$ at the equator in (7) gives

$$
r_{s}^{-1}=\sqrt{\frac{-\rho_{0} w_{\mathrm{AG}}\left(y=0^{\circ}\right)}{\beta \tau_{x}^{\prime}\left(y=0^{\circ}\right)}} .
$$

The $V_{\mathrm{AG}}$ extrema occur where $\partial V_{\mathrm{AG}} / \partial y=0$. From (7), this happens when $r_{s}=|f|$ and leads to 
$\mathrm{V}_{\mathrm{AG}}$ (Mode 1, Spring)

a)

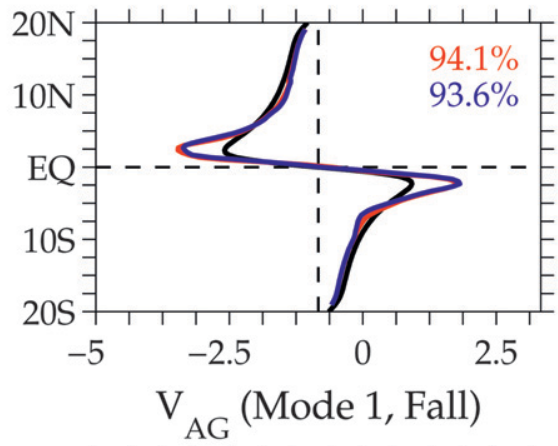

c)

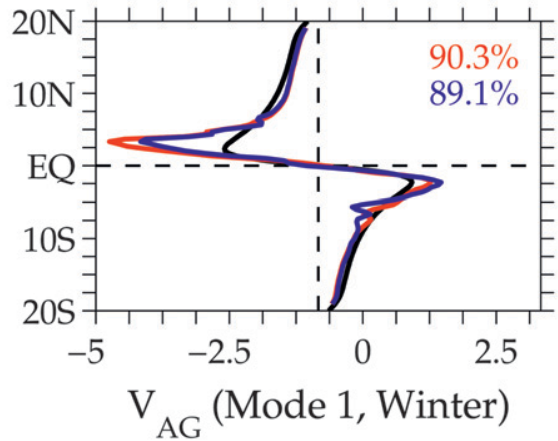

e)

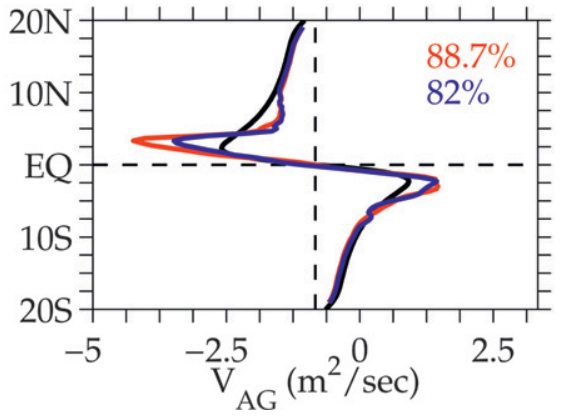

Time Evolution

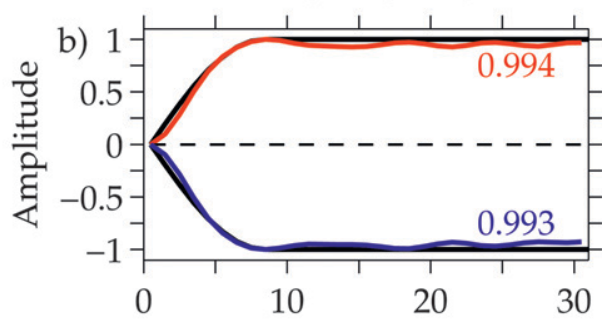

Time Evolution

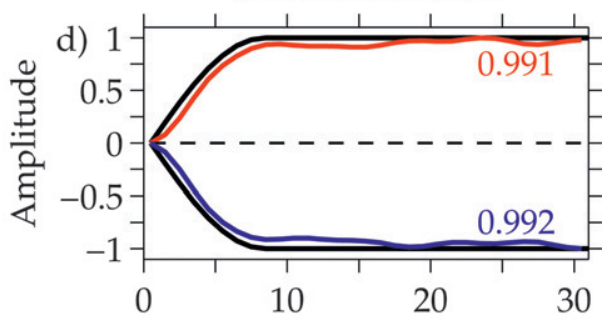

Time Evolution

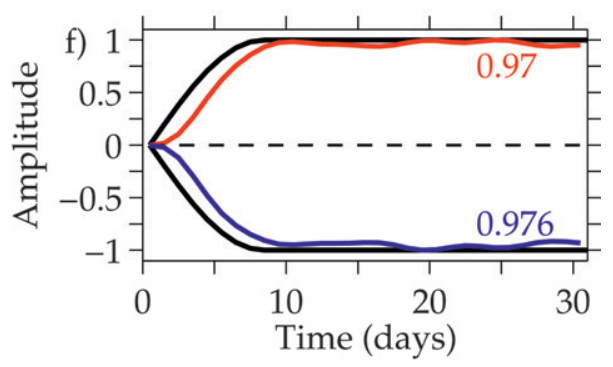

FIG. 15. First EOF mode structure for $V_{\mathrm{AG}}$ along $140^{\circ} \mathrm{W}$ from strengthened trade wind run minus the control run (blue lines) during (left) spring/summer, fall, and winter. Red lines indicate the corresponding curves for weakened trade wind run; $V_{\tau}$ from Fig. 4 is also plotted (black lines). Percentage variance represented by first EOF provided on each panel. (right) Panels overlap the temporal evolution of the appropriate wind anomaly (black lines) with the principal component time series of $V_{\mathrm{AG}}$. Zero-lag correlations with the wind anomaly are provided on each panel.

$$
r_{s}^{-1}=\left(\beta\left|y_{\mathrm{ext}}\right|\right)^{-1}
$$

This gives the magnitude of $V_{\mathrm{AG}}$ at the extrema, which can then be used in (6) to give a third estimate,

$$
r_{s}^{-1}=\frac{2 \rho_{0}\left|V_{\mathrm{AG}}\left(y=y_{\text {ext }}\right)\right|}{\left|\tau_{x}^{\prime}\left(y=y_{\mathrm{ext}}\right)\right|} .
$$

Table 3 compares the values of $r_{s}^{-1}$ obtained from these three methods. Overall, $r_{s}^{-1}=2$ day was a suitable choice for the zonal wind experiments conducted here. This is especially true in spring/summer or when $r_{s}^{-1}$ is estimated from the equatorial value of $w_{\mathrm{AG}}$ or the southern extre- mum of $V_{\mathrm{AG}}\left(r_{s}^{-1}\right.$ between 1.7 and 2.8 day). In the fall and winter, widely differing values are estimated for $r_{s}^{-1}$ based on the latitude ( $r_{s}^{-1}$ as small as 1.3 day) and magnitude $\left(r_{s}^{-1}\right.$ as large as 3.8 day) of the northern extremum reflecting how much the ageostrophic anomalies in the northern TC deviate from the equatorially modified Ekman solution during those time periods.

\section{Summary and conclusions}

The zonal currents in the central equatorial Pacific are strong and have often been observed, giving robust estimates of their strength, spatial structure, and 
$\mathrm{w}_{\mathrm{AG}}$ (Mode 1, Spring)

a)
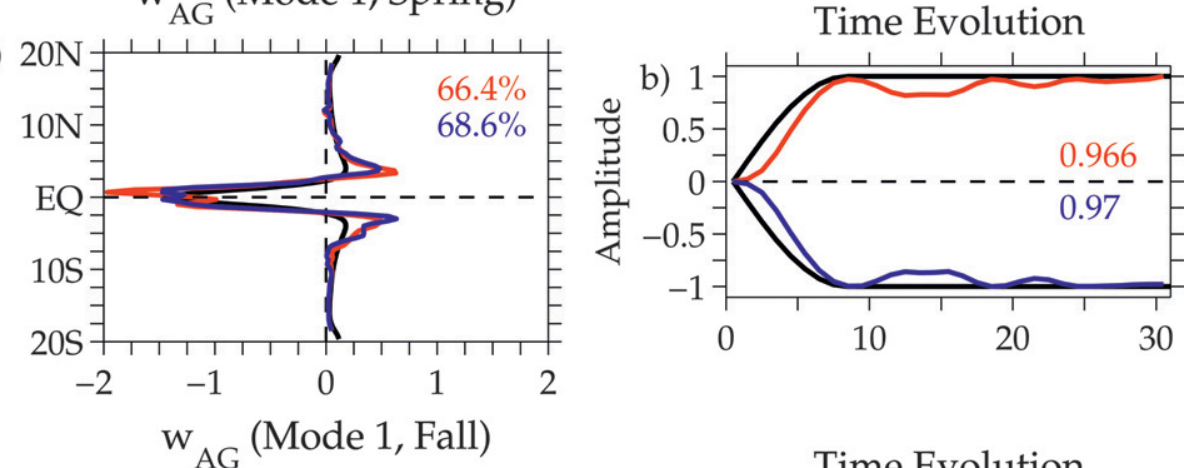

c)
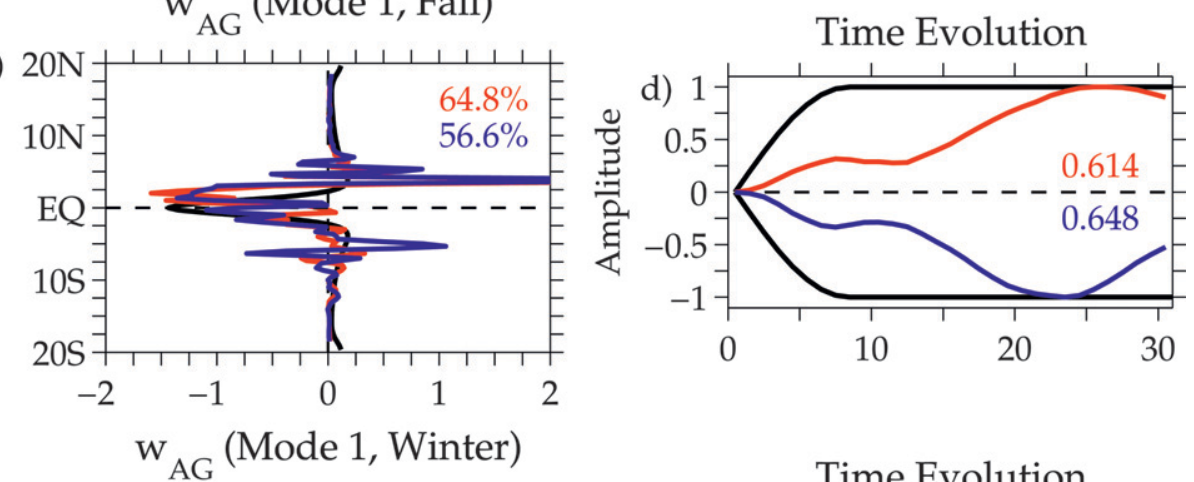

e)

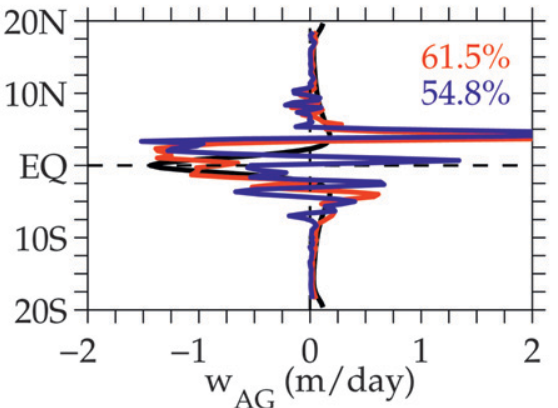

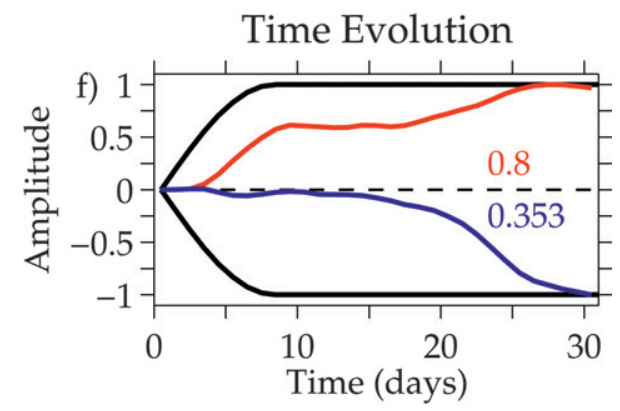

FIG. 16. First EOF mode structure for $w_{\mathrm{AG}}$ along $140^{\circ} \mathrm{W}$ from strengthened trade wind run minus the control run (blue lines) during (left) spring/summer, fall, and winter. Red lines indicate the corresponding curves for weakened trade wind run; $w_{\tau}$ from Fig. 4 is also plotted (black lines). Percentage variance represented by first EOF provided on each panel. (right) Panels overlap the temporal evolution of the appropriate wind anomaly (black lines) with the principal component time series of $w_{\mathrm{AG}}$. Zero-lag correlations with the wind anomaly are provided on each panel.

temporal evolution. Much less is known about the meridional upwelling circulation cells, as we have only sparse measurements of the upper ocean meridional and vertical velocities, and these are often aliased by TIWs. Yet, vertical and meridional heat fluxes have been shown to be more important than zonal heat flux for sustaining the equatorial Pacific cold tongue and its sharp temperature gradients (e.g., Swenson and Hansen 1999). Therefore, better sampling is required of the full three-dimensional circulation across the cold tongue, and this sampling must resolve TIW fluctuations that, themselves, contribute significantly to the heat flux balance (Hansen and Paul 1984; Bryden and
Brady 1989; Baturin and Niiler 1997; Wang and McPhaden 1999; Swenson and Hansen 1999; Wang and McPhaden 2000). In anticipation of these measurements, here we have conducted perturbed trade wind experiments in an OGCM to study the threedimensional structure of velocity in the central equatorial Pacific and the mechanisms by which the TCs respond to wind variations. Findings from this numerical study will aid in the design of future field experiments with the goal of resolving, and adequately sampling, the spatiotemporal structure of the TCs.

To analyze the spindown of the TCs in response to the localized weakening of the trade winds, a series of 
TABLE 2. Extrema, inflection points, and ratio of the magnitude of the northern extremum and southern extremum for 45-day-mean $V_{\mathrm{AG}}$ along $140^{\circ} \mathrm{W}$. For each season, the mean \pm standard deviation of the results for the four different wind anomalies are reported: $A=0.025 \mathrm{~N} \mathrm{~m}^{-2}$ and $A^{*}=A / 10$. Boldface indicates the two weakened trade wind cases presented in section 3 .

\begin{tabular}{|c|c|c|c|c|c|}
\hline Season & $S_{\text {ext }}$ & $S_{\text {infl }}$ & $N_{\text {ext }}$ & $N_{\text {infl }}$ & |Ratiol \\
\hline Spring & $2.17^{\circ} \pm 0.19^{\circ} \mathrm{S}$ & $2.94^{\circ} \pm 0.32^{\circ} \mathrm{S}$ & $2.83^{\circ} \pm 0.33^{\circ} \mathrm{N}$ & $3.68^{\circ} \pm 0.72^{\circ} \mathrm{N}$ & $1.08 \pm 0.03$ \\
\hline Weak $A$ & $2.3^{\circ} \mathrm{S}$ & $3.3^{\circ} \mathrm{S}$ & 3.0 ${ }^{\circ} \mathrm{N}$ & $3.7^{\circ} \mathbf{N}$ & 1.08 \\
\hline Strong $A$ & $2.0^{\circ} \mathrm{S}$ & $2.9^{\circ} \mathrm{S}$ & $3.0^{\circ} \mathrm{N}$ & $4.2^{\circ} \mathrm{N}$ & 1.12 \\
\hline Weak $A^{*}$ & $2.3^{\circ} \mathrm{S}$ & $2.9^{\circ} \mathrm{S}$ & $2.3^{\circ} \mathrm{N}$ & $2.6^{\circ} \mathrm{N}$ & 1.10 \\
\hline Strong $A^{*}$ & $2.0^{\circ} \mathrm{S}$ & $2.6^{\circ} \mathrm{S}$ & $3.0^{\circ} \mathrm{N}$ & $4.1^{\circ} \mathrm{N}$ & 1.04 \\
\hline Fall & $2.33^{\circ} \pm 0.27^{\circ} \mathrm{S}$ & $2.88^{\circ} \pm 0.26^{\circ} \mathrm{S}$ & $3.58^{\circ} \pm 0.17^{\circ} \mathrm{N}$ & $4.42^{\circ} \pm 0.41^{\circ} \mathrm{N}$ & $1.61 \pm 0.16$ \\
\hline Weak $A$ & $2.7^{\circ} \mathrm{S}$ & $3.3^{\circ} \mathrm{S}$ & $3.3^{\circ} \mathrm{N}$ & $4.3^{\circ} \mathrm{N}$ & 1.84 \\
\hline Strong $A$ & $2.3^{\circ} \mathrm{S}$ & $2.8^{\circ} \mathrm{S}$ & $3.7^{\circ} \mathrm{N}$ & $3.9^{\circ} \mathrm{N}$ & 1.48 \\
\hline Weak $A^{*}$ & $2.3^{\circ} \mathrm{S}$ & $2.7^{\circ} \mathrm{S}$ & $3.7^{\circ} \mathrm{N}$ & $4.7^{\circ} \mathrm{N}$ & 1.56 \\
\hline Strong $A^{*}$ & $2.0^{\circ} \mathrm{S}$ & $2.7^{\circ} \mathrm{S}$ & $3.7^{\circ} \mathrm{N}$ & $4.8^{\circ} \mathrm{N}$ & 1.58 \\
\hline Winter & $2.92^{\circ} \pm 0.69^{\circ} \mathrm{S}$ & $3.52^{\circ} \pm 0.70^{\circ} \mathrm{S}$ & $3.58^{\circ} \pm 0.17^{\circ} \mathrm{N}$ & $4.23^{\circ} \pm 0.19^{\circ} \mathrm{N}$ & $1.36 \pm 0.16$ \\
\hline Weak $A$ & $3.3^{\circ} \mathrm{S}$ & $4.1^{\circ} \mathrm{S}$ & $3.3^{\circ} \mathrm{N}$ & $4.0^{\circ} \mathrm{N}$ & 1.39 \\
\hline Strong $A$ & $2.3^{\circ} \mathrm{S}$ & $2.8^{\circ} \mathrm{S}$ & $3.7^{\circ} \mathrm{N}$ & $4.4^{\circ} \mathrm{N}$ & 1.12 \\
\hline Weak $A *$ & $3.7^{\circ} \mathrm{S}$ & $4.1^{\circ} \mathrm{S}$ & $3.7^{\circ} \mathrm{N}$ & $4.2^{\circ} \mathrm{N}$ & 1.46 \\
\hline Strong $A^{*}$ & $2.3^{\circ} \mathrm{S}$ & $3.1^{\circ} \mathrm{S}$ & $3.7^{\circ} \mathrm{N}$ & $4.3^{\circ} \mathrm{N}$ & 1.47 \\
\hline
\end{tabular}

experiments was conducted that added a westerly wind anomaly to the climatological wind stress. To diagnose the role of the background currents and TIWs, the 61day experiments were repeated during three different phases of the annual cycle: boreal spring/summer, fall, and winter. Emphasis was placed on the spring/summer and fall cases, which represent extremes of the annual evolution of the southeasterly trade winds (Figs. 3a,b) and TIWs. Equatorially modified versions of geostrophy and Ekman theory, as well as zonal low-pass filtering, were used to isolate the mechanisms of the largezonal-scale wind-driven response. The near-surface linear response to the imposed weakened trade anomaly is equatorially symmetric eastward transport, equatorial downwelling, antisymmetric equatorward transport with maxima at $2.3^{\circ}$ latitude, and symmetric off-equatorial upwelling with maxima at $4.0^{\circ}$ latitude (Fig. 4).

Weakening the trade winds in any season rapidly weakened the TCs (Figs. 6 and 8). The zonal current shear was also reduced, which had the effect of reducing the amplitude of TIWs in and east of the wind patch. In spring/summer when the background trade winds, TCs, and TIWs were seasonally weak, the largezonal-scale response of the circulation was nearly linear (e.g., equatorially symmetric in $u_{L}, w_{L}$ and antisymmetric in $\left.v_{L}\right)$. In fall, when the background TCs and TIWs

TABLE 3. The $r_{s}^{-1}$ computed from 45-day-mean $w_{\mathrm{AG}}\left(y=0^{\circ} \mathrm{N}\right)$, and location $\left(S_{\text {ext }}\right.$ and $\left.N_{\text {ext }}\right)$ and magnitude of 45 -day-mean $V_{\mathrm{AG}}$ extrema along $140^{\circ} \mathrm{W}$. For each season, the mean \pm standard deviation of the results for the four different wind anomalies is reported: $A=0.025 \mathrm{~N} \mathrm{~m}^{-2}$ and $A^{*}=A / 10$. Boldface indicates the two weakened trade wind cases presented in section 3 .

\begin{tabular}{|c|c|c|c|c|c|}
\hline Season & $w_{\mathrm{AG}}\left(y=0^{\circ} \mathrm{N}\right)$ & $S_{\text {ext }}$ & $V_{A}\left(y=S_{\text {ext }}\right)$ & $N_{\text {ext }}$ & $V_{A}\left(y=N_{\text {ext }}\right)$ \\
\hline Spring & $1.99 \pm 0.06$ & $2.14 \pm 0.19$ & $2.57 \pm 0.09$ & $1.65 \pm 0.22$ & $2.78 \pm 0.03$ \\
\hline Weak $A$ & 1.91 & 1.98 & 2.61 & 1.54 & 2.81 \\
\hline Strong $A$ & 2.04 & 2.31 & 2.46 & 1.54 & 2.75 \\
\hline Weak $A^{*}$ & 2.00 & 1.98 & 2.55 & 1.98 & 2.79 \\
\hline Strong $A^{*}$ & 1.99 & 2.31 & 2.66 & 1.54 & 2.77 \\
\hline Fall & $1.67 \pm 0.26$ & $2.00 \pm 0.24$ & $2.35 \pm 0.09$ & $1.29 \pm 0.06$ & $3.78 \pm 0.24$ \\
\hline Weak $A$ & 1.50 & 1.73 & 2.22 & 1.38 & 4.07 \\
\hline Strong $A$ & 2.03 & 1.98 & 2.37 & 1.26 & 3.50 \\
\hline Weak $A^{*}$ & 1.46 & 1.98 & 2.40 & 1.26 & 3.73 \\
\hline Strong $A^{*}$ & 1.68 & 2.31 & 2.43 & 1.26 & 3.83 \\
\hline Winter & $2.01 \pm 0.06$ & $1.65 \pm 0.38$ & $2.41 \pm 0.17$ & $1.29 \pm 0.06$ & $3.26 \pm 0.31$ \\
\hline Weak $A$ & 1.96 & 1.38 & 2.56 & 1.38 & 3.55 \\
\hline Strong $A$ & 1.99 & 1.98 & 2.54 & 1.26 & 2.85 \\
\hline Weak $A^{*}$ & 2.10 & 1.26 & 2.34 & 1.26 & 3.41 \\
\hline Strong $A^{*}$ & 1.98 & 1.98 & 2.21 & 1.26 & 3.24 \\
\hline
\end{tabular}


were seasonally strong, the anomalous circulation under the wind patch was equatorially asymmetric with a strong narrow band of anomalous upwelling produced north of the equator. The fall experiments showed evidence of nonlinear rectification by the modified TIWs onto the TCs east of the wind patch, especially north of the equator. This rectification likely also occurred under the wind patch itself but was difficult to separate from the large nonlinear interactions with the seasonally strong TCs.

Along $140^{\circ} \mathrm{W}$, the linear equatorially modified Ekman solutions with vertical shear dissipation rate $r_{s}=(2$ day $)^{-1}$ largely explained the anomalous ageostrophic response of the TCs. In spring/summer, the meridional structure of the means and first-mode EOFs of ( $V_{\mathrm{AG}}$, $\left.w_{\text {AG }}\right)$ were very similar to those of $\left(V_{\tau}, w_{\tau}\right)$, and the temporal evolution of the principal component time series matched the time evolution of the anomalous winds with lags of less than a day. In fall, however, equatorially asymmetric divergence in $V_{\mathrm{AG}}$ produced a sharp off-equatorial peak in $w_{\mathrm{AG}}$ near $4^{\circ} \mathrm{N}$, which intensified as the anomalous TIWs grew in amplitude. Within a given season, the ageostrophic responses in the TCs were mostly linear so that applying an anomaly of opposite sign produced a nearly identical cell structure with mirror-image time series. The largest differences in the TC structure occurred between seasons, and the most significant nonlinearities were found for $w_{\mathrm{AG}}$ in fall and winter.

The extrema and inflection points of near-surface $V_{\mathrm{AG}}$ were used to define the transition from an equatorial to Ekman dynamical response. Based on the dominant contribution of $\partial V_{\mathrm{AG}} / \partial y$ to $w_{\mathrm{AG}}$, the inflection points of $V_{\mathrm{AG}}$ correspond to off-equatorial extrema of $w_{\mathrm{AG}}$. During the spring/summer weak wind season, the extrema and inflection points were relatively close to the equator and $r_{s}^{-1}=2$ day was a suitable choice for the zonal wind experiments. In fall/ winter, the extrema and inflection points were shifted poleward by up to $1.6^{\circ}$, and widely differing values were estimated for $r_{s}^{-1}$ from the location and magnitude of the northern extreme (ranging from 1.3 day to 3.8 day).

The source of these interseasonal differences are nonlinear interactions with the background TCs and nonlinear rectification by the TIWs. Quantification of the relative contributions of the two hypothesized sources of nonlinearity is needed to understand the equatorial asymmetry of the TCs in the central equatorial Pacific. How little is known about these nonlinear interactions points to the need for cross-equatorial velocity measurements that can resolve the influence of asymmetric zonal current shears on the TIWs and the influence of TIWs on the equatorial asymmetry of the
TCs. Based on the substantial contribution of $\partial V / \partial y$ to $w$ in the model, the broad off-equatorial downwelling in spring/summer can probably be measured from synoptic measurements of meridional velocity with relatively coarse meridional sampling along $140^{\circ} \mathrm{W}$ (as long as there is adequate temporal resolution to filter out the seasonally weak TIWs). In contrast, fine meridional sampling $\left(0.5^{\circ}\right.$ or better $)$ and sampling along adjacent meridians are required in fall and winter to determine whether and how the sharp narrow band of downwelling near $4^{\circ} \mathrm{N}$ results from rectification by TIWs.

Acknowledgments. The authors thank Andrew Wittenberg, Stephen Griffies, and MOM4 modeling community for helpful discussions about the model viscosity scheme and its impact on the model TIWs. Special thanks to Andrew Wittenberg for running the climatological spinup on the NOAA/GFDL supercomputer. We also thank Craig Risien, Dudley Chelton, and Michael Schlax for distributing an early version of the QuikSCAT climatology, and Greg Johnson for providing shipboard ADCP data. Comments from Meghan Cronin, Dennis Moore, Jacyln Brown, and an anonymous reviewer led to significant improvements in the paper. The authors were funded by NOAA/CPO, and this research was performed while RCP held an NRC Research Associateship Award at NOAA/PMEL.

\section{APPENDIX}

\section{Details of Geostrophic Adjustment}

\section{a. $u_{g}$ adjustment}

To compute $u_{g}$ near the equator along a meridian $x_{0}$, the Picaut and Tournier (1991) adjustment to the dynamic heights can be written as

$$
\widehat{\Phi}\left(x_{0}, y\right)=\Phi\left(x_{0}, y\right)+\Phi^{\prime}\left(x_{0}, y\right),
$$

where

$$
\Phi^{\prime}\left(x_{0}, y\right)=-\Phi_{y}\left(x_{0}, 0\right) y e^{-y^{2} / L^{2}},
$$

and the decay length scale has been chosen to be $L=$ $2^{\circ}$. This adjustment ensures continuity of $u_{g}$ across the equator and preserves its nonsingular solution at the equator (section 2c). This can be seen from the first and second meridional derivatives of $\widehat{\Phi}\left(x_{0}, y\right)$ :

$$
\widehat{\Phi}_{y}\left(x_{0}, y\right)=\Phi_{y}\left(x_{0}, y\right)-\Phi_{y}\left(x_{0}, 0\right)\left(1-\frac{2 y^{2}}{L^{2}}\right) e^{-y^{2} / L^{2}},
$$




$$
\begin{aligned}
\widehat{\Phi}_{y y}\left(x_{0}, y\right)= & \Phi_{y y}\left(x_{0}, y\right)-\Phi_{y}\left(x_{0}, 0\right)\left(\frac{2 y}{L^{2}}\right) \\
& \times\left(\frac{2 y^{2}}{L^{2}}-3\right) e^{-y^{2} / L^{2}} .
\end{aligned}
$$

Note that $\widehat{\Phi}_{y}\left(x_{0}, 0\right)=0$, and $\widehat{\Phi}_{y y}\left(x_{0}, 0\right)=\Phi_{y y}\left(x_{0}, 0\right)$.

\section{b. $u_{g}$ and $v_{g}$ adjustment}

To estimate both $u_{g}$ and $v_{g}$ near the equator, dynamic heights along the meridians $x_{0}$ and $x_{0} \pm \Delta x$ are modified by an additional adjustment term that affects only the $x$ derivative:

$$
\widehat{\Phi}(x, y)=\Phi(x, y)+\Phi^{\prime}\left(x_{0}, y\right)+\Phi^{\prime \prime}(x, y),
$$

where

$$
\Phi^{\prime \prime}(x, y)=-\Phi_{x}\left(x_{0}, 0\right)\left(x-x_{0}\right) e^{-y^{2} / L^{2}} .
$$

Note $\Phi^{\prime}\left(x_{0}, y\right)$ is still given by (A2) and $L=2^{\circ}$ for both adjustment terms. The $\Phi^{\prime \prime}(x, y)$ term ensures the continuity of $v_{g}$ across the equator and preserves its nonsingular solution at the equator (section $2 \mathrm{c}$ ). This can be seen from the $x$ and $x y$ derivatives of $\widehat{\Phi}(x, y)$. The correction $\Phi^{\prime}\left(x_{0}, y\right)$ does not depend on $x$; therefore the $x$ derivatives have the form

$$
\widehat{\Phi}_{x}(x, y)=\Phi_{x}(x, y)-\Phi_{x}\left(x_{0}, 0\right) e^{-y^{2} / L^{2}},
$$

which reduces to zero at the equator, and

$$
\widehat{\Phi}_{x y}(x, y)=\Phi_{x y}(x, y)+\Phi_{x}\left(x_{0}, 0\right)\left(\frac{2 y}{L^{2}}\right) e^{-y^{2} / L^{2}},
$$

which reduces to $\Phi_{x y}(x, 0)$ at the equator. The Picaut and Tournier (1991) $u_{g}$ adjustment given by Eqs. (A3)(A4) is also preserved as $\Phi^{\prime \prime}(x, y)$ vanishes when $x=x_{0}$. Continuous zonal and meridional geostrophic velocities along $x=x_{0}$ can then be computed using (A3) and (A7) away from the equator and (A4) and (A8) at the equator (section 2c).

\section{REFERENCES}

Baturin, N. G., and P. P. Niiler, 1997: Effects of instability waves in the mixed layer of the equatorial Pacific. J. Geophys. Res., 102, 27 771-27 793.

Bonjean, F., and G. S. E. Lagerloef, 2002: Diagnostic model of the surface currents in the tropical Pacific Ocean. J. Phys. Oceanogr., 32, 2938-2954.

Brown, J. N., J. S. Godfrey, and R. Fiedler, 2007a: A zonal momentum balance on density layers for the central and eastern equatorial Pacific. J. Phys. Oceanogr., 37, 1939-1955.

,-- , and A. Schiller, 2007b: A discussion of flow pathways in the central and eastern equatorial Pacific. J. Phys. Oceanogr., 37, 1321-1339.
Bryden, H., and E. C. Brady, 1989: Eddy momentum and heat fluxes and their effects on the circulation of the equatorial Pacific Ocean. J. Mar. Res., 47, 55-79.

Chelton, D. B., F. J. Wentz, C. L. Gentemann, R. A. de Szoeke, and M. G. Schlax, 2000: Satellite microwave SST observations of transequatorial tropical instability waves. Geophys. Res. Lett., 27, 1239-1242.

_- and Coauthors, 2001: Observations of coupling between surface wind stress and sea surface temperature in the eastern tropical Pacific. J. Climate, 14, 1479-1498.

Contreras, R. F., 2002: Long-term observations of tropical instability waves. J. Phys. Oceanogr., 32, 2715-2722.

Cox, M. D., 1980: Generation and propagation of 30-day waves in a numerical model of the Pacific. J. Phys. Oceanogr., 10, 1168-1186.

de Szoeke, S. P., S.-P. Xie, T. Miyama, K. J. Richards, and R. J. O. Small, 2007: What maintains the SST front north of the eastern Pacific equatorial cold tongue? J. Climate, 20, 2500-2514.

Donohue, K. A., and M. Wimbush, 1998: Model results of flow instabilities in the tropical Pacific Ocean. J. Geophys. Res., 103, 21 401-21 412.

Griffies, S. M., M. J. Harrison, R. C. Pacanowski, and A. Rosati, 2003: A technical guide to MOM4. GFDL Ocean Group Tech. Rep. 5, NOAA/Geophysical Fluid Dynamics Laboratory, $295 \mathrm{pp}$.

_ global climate simulations. Ocean Sci., 1, 45-79.

Hansen, D. V., and C. A. Paul, 1984: Genesis and effects of long waves in the equatorial Pacific. J. Geophys. Res., 89, $10431-10440$.

Hayes, S. P., L. J. Mangum, J. Picaut, A. Sumi, and K. Takeuchi, 1991: TOGA-TAO: A moored array for real-time measurements in the tropical Pacific Ocean. Bull. Amer. Meteor. Soc., 72, 339-347.

Hazeleger, W., P. de Vries, and G. J. van Oldenborgh, 2001: Do tropical cells ventilate the Indo-Pacific equatorial thermocline? Geophys. Res. Lett., 28, 1763-1766.

Johnson, E. S., and D. S. Luther, 1994: Mean zonal momentum balance in the upper and central equatorial Pacific Ocean. $J$. Geophys. Res., 99, 7689-7705.

Johnson, G. C., M. J. McPhaden, and E. Firing, 2001: Equatorial Pacific ocean horizontal velocity, divergence, and upwelling. J. Phys. Oceanogr., 31, 839-849.

_ B. M. Sloyan, W. S. Kessler, and K. E. McTaggart, 2002: Direct measurements of upper ocean currents and water properties across the tropical Pacific Ocean during the 1990s. Prog. Oceanogr., 52, 31-61.

Kessler, W. S., and B. A. Taft, 1987: Dynamic heights and zonal geostrophic transports in the central tropical Pacific during 1979-84. J. Phys. Oceanogr., 17, 97-122.

, L. M. Rothstein, and D. Chen, 1998: The annual cycle of SST in the eastern tropical Pacific, diagnosed in an ocean GCM. J. Climate, 11, 777-799.

Kröger, J., A. J. Busalacchi, J. Ballabrera-Poy, and P. MalanotteRizzoli, 2005: Decadal variability of shallow cells and equatorial sea surface temperature in a numerical model of the Atlantic. J. Geophys. Res., 110, C12003, doi:10.1029/ 2004JC002703.

Lagerloef, G. S. E., G. T. Mitchum, R. B. Lukas, and P. P. Niiler, 1999: Tropical Pacific near-surface currents estimated from altimeter, wind, and drifter data. J. Geophys. Res., 104, 23 313-23 326.

Large, W. G., G. Danabasoglu, J. C. McWilliams, P. R. Gent, and F. O. Bryan, 2001: Equatorial circulation of a global ocean 
climate model with anisotropic horizontal viscosity. J. Phys. Oceanogr., 31, 518-536.

Legeckis, R., 1977: Long waves in the equatorial Pacific Ocean: A view from a geostationary satellite. Science, 197, 1179-1181.

Lu, P., J. P. McCreary, and B. A. Klinger, 1998: Meridional circulation cells and the source waters of the Pacific equatorial undercurrent. J. Phys. Oceanogr., 28, 62-84.

Lyman, J. M., 2002: The cross-equatorial structure of tropical instability waves in sea surface height. Ph.D. thesis, Oregon State University, $134 \mathrm{pp}$.

, D. B. Chelton, R. A. de Szoeke, and R. M. Samelson, 2005: Tropical instability waves as a resonance between equatorial Rossby waves. J. Phys. Oceanogr., 35, 232-254.

—, G. C. Johnson, and W. S. Kessler, 2007: Distinct 17- and 33-day tropical instability waves in subsurface observations. J. Phys. Oceanogr., 37, 855-872.

McPhaden, M. J., 1993: TOGA-TAO and the 1991-93 El NiñoSouthern Oscillation event. Oceanography, 6, 36-44.

Nonaka, M., S.-P. Xie, and J. P. McCreary, 2002: Decadal variations in the subtropical cells and equatorial Pacific SST. Geophys. Res. Lett., 29, 1116, doi:10.1029/2001GL013717.

Philander, S. G. H., 1978: Instabilities of zonal equatorial currents, Part 2. J. Geophys. Res., 83, 3679-3682.

Picaut, J., and R. Tournier, 1991: Monitoring the 1979-1985 equatorial Pacific current transports with expendable bathythermograph data. J. Geophys. Res., 96, 3263-3277.

Qiao, L., and R. H. Weisberg, 1995: Tropical instability wave kinematics: Observations from the Tropical Instability Wave Experiment. J. Geophys. Res., 100, 8677-8693.

Reverdin, G., C. Frankignoul, E. Kestenare, and M. J. McPhaden, 1994: Seasonal variability in the surface currents of the equatorial Pacific. J. Geophys. Res., 99, 20 323-20 344.

Risien, C. M., and D. B. Chelton, 2008: A global climatology of surface wind and wind stress fields from eight years of QuikSCAT scatterometer data. J. Phys. Oceanogr., 38, 2379-2413.

Schlax, M. G., and D. B. Chelton, 1992: Frequency domain diagnostics for linear smoothers. J. Amer. Stat. Assoc., 87, 1070 1081.
Seo, H., M. Jochum, R. Murtugudde, A. J. Miller, and J. O. Roads, 2007: Feedback of tropical instability-wave-induced atmospheric variability onto the ocean. J. Climate, 23, 58425855.

Steele, M., R. Morley, and W. Ermold, 2001: PHC: A global ocean hydrography with a high-quality Arctic Ocean. J. Climate, 14, 2079-2087.

Swenson, M. S., and D. V. Hansen, 1999: Tropical Pacific Ocean mixed layer heat budget: The Pacific cold tongue. J. Phys. Oceanogr., 29, 69-81.

Wang, W., and M. J. McPhaden, 1999: The surface-layer heat balance in the equatorial Pacific Ocean. Part I: The mean seasonal cycle. J. Phys. Oceanogr., 29, 1812-1831.

— and - 2000: The surface-layer heat balance in the equatorial Pacific Ocean. Part II: Interannual variability. J. Phys. Oceanogr., 30, 2989-3008.

Weisberg, R. H., and L. Qiao, 2000: Equatorial upwelling in the central Pacific estimated from moored velocity profilers. $J$. Phys. Oceanogr., 30, 105-124.

Wittenberg, A. T., 2002: ENSO response to altered climate. Ph.D. thesis, Princeton University, 475 pp.

— A. Rosati, N.-C. Lau, and J. J. Ploshay, 2006: GFDL's CM2 global coupled climate models. Part III: Tropical Pacific climate and ENSO. J. Climate, 19, 698-722.

Wyrtki, K., 1981: An estimate of equatorial upwelling in the Pacific. J. Phys. Oceanogr., 11, 1205-1214.

Yu, L., and R. A. Weller, 2007: Objectively analyzed air-sea heat fluxes for the global ice-free oceans (1981-2005). Bull. Amer. Meteor. Soc., 88, 527-539.

,-- , and B. Sun, 2004: Improving latent and sensible heat flux estimates for the Atlantic Ocean (1988-99) by a synthesis approach. J. Climate, 17, 373-393.

Zhang, Y., W. B. Rossow, A. A. Lacis, V. Oinas, and M. I. Mishchenko, 2004: Calculation of radiative fluxes from the surface to top of atmosphere based on ISCCP and other global data sets: Refinements of the radiative transfer model and the input data. J. Geophys. Res., 109, D19105, doi:10. 1029/2003JD004457. 